Mainstreaming Genetic Testing for Epithelial Ovarian Cancer by Oncology Providers: A Survey of Current Practice

by

Megan Ann Czekalski

BS, Bucknell University, 2019

Submitted to the Graduate Faculty of the

Department of Human Genetics

Graduate School of Public Health in partial fulfillment

of the requirements for the degree of

Master of Science

University of Pittsburgh

2021 


\section{UNIVERSITY OF PITTSBURGH}

\section{GRADUATE SCHOOL OF PUBLIC HEALTH}

This thesis was presented

by

\section{Megan Ann Czekalski}

It was defended on

April 13th, 2021

and approved by

Andrea L. Durst, MS, DrPH, CGC, Assistant Professor, Associate Director, Genetic Counseling

Program, Co-Director, MPH in Public Health Genetics Program, Department of Human Genetics, Graduate School of Public Health, University of Pittsburgh

Phuong Mai, MD, MS, Associate Professor, Department of Obstetrics, Gynecology, and Reproductive Sciences, School of Medicine, University of Pittsburgh

Thesis Advisor: Rachelle C. Huziak, MS, CGC, Adjunct Faculty, Senior Genetic Counselor, UPMC Cancer Genetics Program 
Copyright (C by Megan Ann Czekalski 


\title{
Mainstreaming Genetic Testing for Epithelial Ovarian Cancer by Oncology Providers: A Survey of Current Practice
}

\author{
Megan Ann Czekalski, MS \\ University of Pittsburgh, 2021
}

\begin{abstract}
With significant deficits in early detection and poor treatment response, ovarian cancer is a devastating diagnosis for many women. Up to $25 \%$ of epithelial ovarian cancer (EOC) is due to a hereditary predisposition, most commonly in BRCA1 and BRCA2. Pathogenic variants in $B R C A 1$, for example, confer a $45 \%$ lifetime risk of EOC; whereas, the general population risk is only 1-2\%. Knowledge of an affected individual's genetic status can have significant implications for treatment and prognosis. Women with pathogenic variants in BRCAl/2 have an enhanced response to platinum-based chemotherapy and poly ADP-ribose polymerase (PARP) inhibitors, leading to an improved prognosis. Identifying individuals who harbor pathogenic variants in ovarian cancer predisposition genes is therefore of critical importance.

Current National Comprehensive Cancer Network ( $\mathrm{NCCN})$ guidelines recommend that all individuals diagnosed with EOC be offered germline genetic testing. While this would ideally be performed by genetics professionals, a shortage of genetic counselors precludes timely access to these services. This study sought to investigate the current genetic testing practices of oncology providers in order to determine the feasibility of oncologist-led genetic testing for patients with EOC. A survey was distributed to members of the Society of Gynecologic Oncologists with questions regarding timing, frequency, and type of genetic testing, referrals to genetics professionals, confidence with aspects of genetics services, and any barriers that currently hinder these processes. Results of the study were encouraging, with the majority of providers always
\end{abstract}


ordering genetic testing for patients with EOC; testing was most commonly ordered at diagnosis and was typically multi-gene panel testing that included $B R C A 1 / 2$, consistent with current recommendations. Provider confidence with the genetic testing process was generally high, especially for deciding which patients to refer to genetics professionals. Patient disinterest and concerns for insurance coverage were commonly cited barriers to testing and referrals. Thus, oncologist-led genetic testing for patients with EOC, with referrals to genetics professionals when appropriate, has the potential to be a viable alternative service delivery model and warrants additional investigation. 


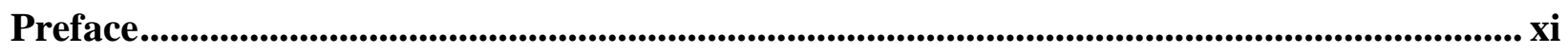

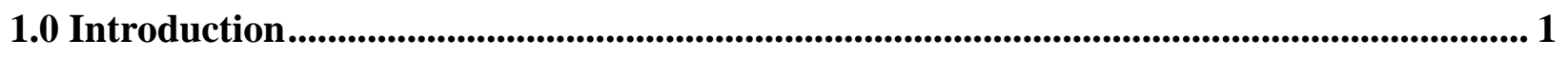

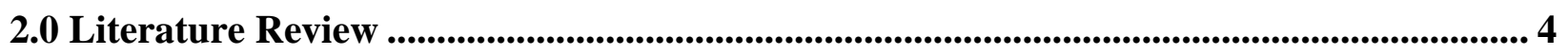

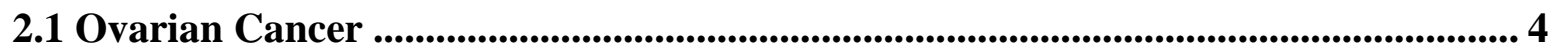

2.1.1 Screening and Surveillance .....................................................................................4

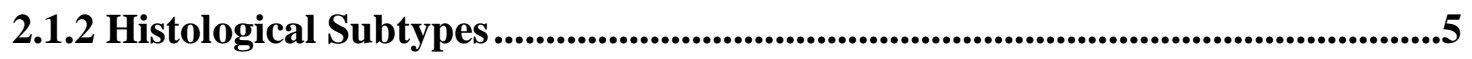

2.1.3 Risk and protective factors for epithelial ovarian cancer ..............................6

2.2 Genetic Predispositions to Ovarian Cancer .......................................................... 8

2.2.1 BRCA1 and $B R C A 2$............................................................................................9

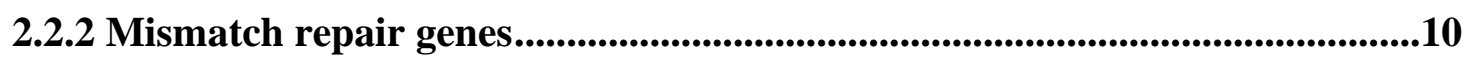

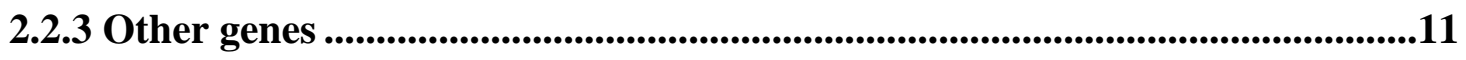

2.3 Ovarian Cancer Genetic Testing....................................................................................... 12

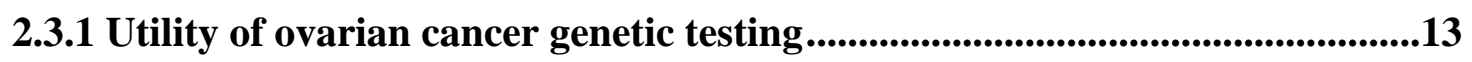

2.3.1.1 BRCA1/2: Management and Screening ........................................... 13

2.3.1.2 Mismatch repair genes: Management and Screening ....................... 15

2.3.1.3 Other genes: Management and Screening........................................... 16

2.3.2 Factors that Influence Genetic Testing Decisions .......................................17

2.3.3 Psychological Impact of Genetic Testing Results..............................................19

2.4 Alternative Service Delivery Models .................................................................... 19

2.4.1 Cancer Genetic Testing by Non-Genetic Health Professionals.....................20

2.4.1.1 Knowledge Gaps and Educational Needs ........................................... 21 
2.4.1.2 Motivations for and barriers to cancer genetics referrals ................. 22

2.4.1.3 Adverse effects of incorrect testing and non-referrals ....................... 23

2.4.2 Oncologist-Led Genetic Testing for Epithelial Ovarian Cancer Patients.....24

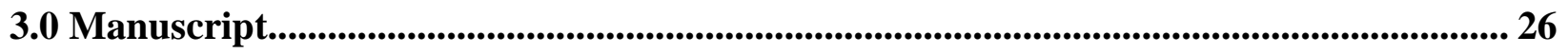

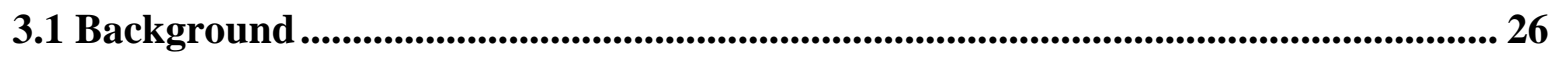

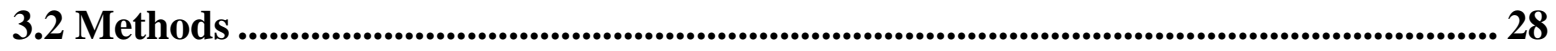

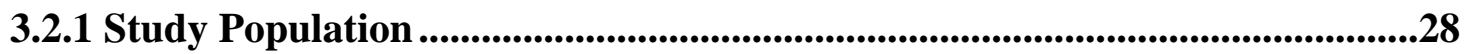

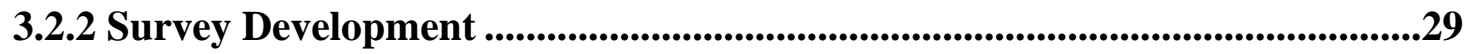

3.2.3 Recruitment and Survey Distribution......................................................30

3.2.4 Data Analysis

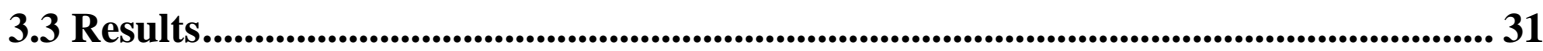

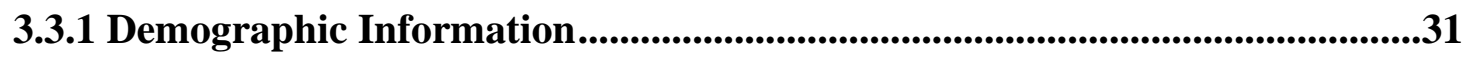

3.3.2 Ordering, Treatment, and Referral Practices .................................................33

3.3.3 Genetics Education ..............................................................................................37

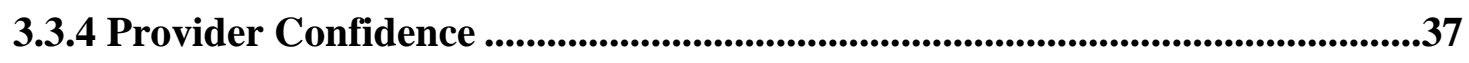

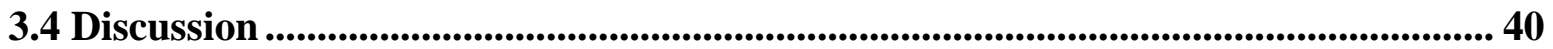

3.4.1 Current Genetic Testing and Referral Practices by Oncology Providers ....40

3.4.2 Types of Genetics Education .........................................................................43

3.4.3 Confidence Levels of Oncology Providers with Genetic Testing Process .....44

3.4.4 Study Limitations and Future Directions ...........................................................45

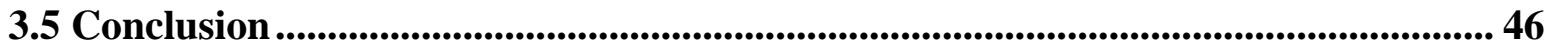

4.0 Relevance to Genetic Counseling and Public Health ...................................................... 47

Appendix A IRB Approval................................................................................................................. 49 


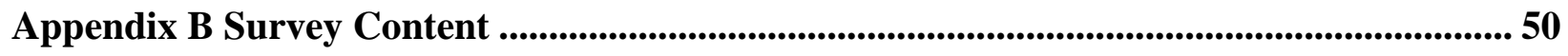

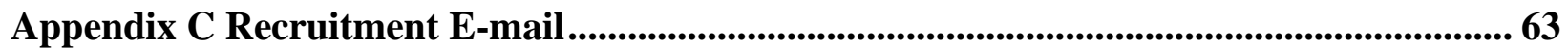

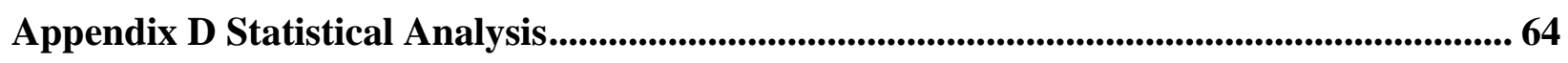

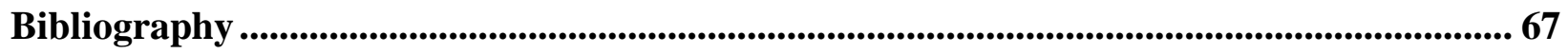




\section{List of Tables}

Table 1 Distribution of histological subtype of invasive epitheical ovarian carcinomas........ 6

Table 2 Risk and protective factors for invasive epithelial ovarian cancer............................. 7

Table 3. Respondent Demographic Information................................................................... 32

Table 4. Treatment and Referral Tendencies by Testing Practice....................................... 33

Table 5. Provider Confidence with Aspects of Cancer Genetics Services by Testing Practices 


\section{List of Figures}

Figure 1. Percentage of providers who ordered genetic testing at indicated times in patient

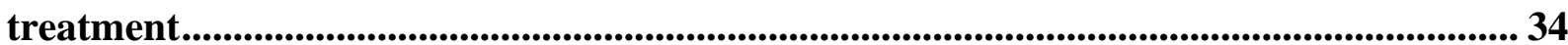

Figure 2. Percentage of providers who ordered indicated type of genetic testing ................ 35

Figure 3. Percentage of providers who referred patients to cancer genetics services at

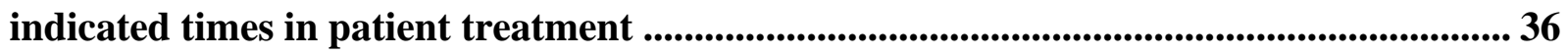




\section{Preface}

I would like to extend my gratitude to my committee members for their hard work and dedication to this study. Rachelle Huziak, my committee chair, Dr. Andrea Durst, and Dr. Phuong Mai assisted me on numerous occasions with their expertise in clinical cancer genetics. I would also like to offer thanks to Dr. Sarah Taylor, who was instrumental in the distribution of the survey. Finally, I would like to thank my family, friends, and colleagues for their support and encouragement. 


\subsection{Introduction}

Ovarian cancer is the $5^{\text {th }}$ leading cause of cancer death for women in the United States, as difficulties in early detection and treatment response often lead to a poor prognosis. Most ovarian cancers are not diagnosed until advanced stages, where the 5 -year survival rate is only $29 \% .^{1}$ Importantly, 20-25\% of epithelial ovarian cancer (EOC) is related to a hereditary predisposition. ${ }^{2}$ The majority of pathogenic variants occur in BRCA1 and BRCA2. Mismatch repair genes related to Lynch syndrome such as $M L H 1, P M S 2, M S H 2, M S H 6$, and EPCAM also contribute to ovarian cancer cases, as well as other moderate-risk genes. ${ }^{3}$ Due to the high rate of germline pathogenic variants, current NCCN, ASCO, and SGO guidelines recommend that all women diagnosed with EOC be offered genetic testing. ${ }^{4-6}$

For affected individuals, standard-of-care treatment for late-stage ovarian cancer is surgery and platinum-based chemotherapy. Women with pathogenic variants in $B R C A 1 / 2$ or other genes that disrupt homologous recombination, whether germline or somatic, have favorable response to poly ADP-ribose polymerase (PARP) inhibitors. ${ }^{7}$ These women therefore often have an improved prognosis. ${ }^{8}$ Similarly, patients with pathogenic variants in mismatch repair genes have targeted immunotherapy treatment options and often have improved survival compared to most patients. ${ }^{9}$ Knowledge of genetic status is therefore critical in tailoring treatments and informing prognosis.

Current screening methods for ovarian cancer are ineffective and do not improve survival of patients. ${ }^{10,11}$ For women at a significantly increased risk of developing EOC, risk-reducing surgery is the most effective preventative measure. ${ }^{12}$ Germline genetic testing is therefore essential in order to identify at-risk individuals; tumor testing alone is not sufficient. Many of the genes implicated in ovarian cancer predispositions have additional cancer risks where additional 
screening and risk-reducing interventions could be considered., ${ }^{4}$ Pathogenic variants in the $B R C A 1 / 2$ genes substantially increase the risk for breast cancer and have additional risks for male breast, prostate, pancreatic, and melanoma cancers. ${ }^{14}$ In the mismatch repair genes, pathogenic variants result in significantly increased risks for colorectal and endometrial cancers and slightly increased risks for skin, gastric, bile duct, small bowel, and pancreatic cancers. ${ }^{13}$ Not only does this knowledge help to inform care for the patient, but at-risk family members can also be evaluated to clarify if their risks are elevated or at the general population level. Germline testing for ovarian cancer predisposition genes is therefore useful in informing patients and their families of potential inherited cancer risks.

Unfortunately, there is limited capacity for patients to be seen by a genetics healthcare professional, and long wait times can seriously hinder appropriate testing and counseling for individuals. ${ }^{15}$ Certain patient characteristics have also been shown to be associated with less genetic testing, including Black race, greater poverty, and less insurance. ${ }^{16} \mathrm{~A}$ recent study found that only $35 \%$ of women with ovarian cancer have received genetic testing despite current guidelines. ${ }^{17}$ Comprehensive knowledge of the factors that are limiting genetic testing of patients with EOC are still not fully understood. In light of this issue, there has been a call to mainstream germline genetic testing by oncologists for patients with EOC. Studies in the United Kingdom have shown favorable outcomes with this service delivery model including high patient and provider satisfaction, rapid turnaround time, and appropriate referrals. ${ }^{18,19}$ It is not only critical that oncologists order appropriate testing and utilize the results to guide treatment, but they must also refer patients with positive or unclear results to genetics services to ensure comprehensive care.

This study sought to investigate the current practices for genetic testing in patients diagnosed with EOC by oncology providers. A survey was sent to members of the Society of 
Gynecologic Oncologists, including oncologists, physician assistants, and nurses. Information collected included the type, frequency, and timing of genetic testing as well as referrals to genetics providers and questions to elucidate barriers to testing and referrals.

The specific aims of this study were as follows:

a) To assess the current practices of oncology providers regarding the ordering and use of genetic testing in patients with epithelial ovarian cancer

b) To identify the frequency with which oncology providers make referrals to genetics professionals for their patients

c) To evaluate the prevalence and types of genetics education that oncology providers have received

d) To identify the comfort level of oncology providers with different aspects of cancer genetics services

The results of this study will help to identify successes and barriers that currently exist in the United States regarding the mainstreaming of genetic testing for patients with EOC. Future studies can further investigate ways to streamline this pathway, address any issues that exist, and improve the patient experience. 


\subsection{Literature Review}

\subsection{Ovarian Cancer}

In 2018, the World Health Organization (WHO) estimated the incidence of ovarian cancer diagnoses to be 295,414 globally; at the same point in time, there were 184,799 new ovarian cancer deaths. ${ }^{20}$ In the United States alone, the incidence of ovarian cancer is 14.8 in 100,000 women. ${ }^{21}$ Most women are diagnosed after menopause; it is rare for women under the age of 40 to have ovarian cancer. ${ }^{22}$ As the $5^{\text {th }}$ leading cause of cancer death in women, the 5-year survival rate for invasive ovarian cancer at all stages is $47 \%$. For metastatic stages-which compromises $59 \%$ of diagnoses - the 5-year survival rate drops to $28 \% .^{1}$

\subsubsection{Screening and Surveillance}

A deficit in the ability to detect ovarian cancer early results in most women being diagnosed at later stages of the disease, contributing to a poor prognosis. When still localized, the 5-year survival rate of ovarian cancer is $92 \% .^{1}$ Vague and non-specific symptoms such as frequent urination, feeling full quickly, abdominal pain, and bloating can arise, but these often do not present until advanced stages of the disease, if at all. ${ }^{10}$ Attempts to detect ovarian cancer earlier through screening measures have been studied. A randomized control trial with 78,216 averagerisk women either receiving normal gynecologic care or an annual transvaginal ultrasound combined with cancer antigen 125 (CA-125) screening did not result in a decrease in mortality nor a stage shift. Additionally, the screening program had a false positive rate of $5 \%$, and the invasive 
diagnostic follow-up procedure resulted in serious medical complications in $15 \%$ of the study participants. ${ }^{10}$

Some screening studies have found evidence of a slight increase in early detection of ovarian cancer. A randomized control trial with average-risk women in Japan found that a higher proportion of women were diagnosed at Stage I in the screening group (63\%) compared to the control group (38\%), but this difference was not statistically significant. ${ }^{23}$ Additional studies have examined serial CA-125 screening with scores using the Risk of Ovarian Cancer Algorithm (ROCA) in either average-risk women or women with a significant family history or a $B R C A 1 / 2$ pathogenic variant. ${ }^{11,24-26}$ ROCA utilizes CA-125 data from thousands of women to determine the risk of having ovarian cancer based on CA-125 fluctuations. The researchers obtained a baseline CA-125 level for each woman, and ROCA was recalculated with every serial CA-125 value. If ROCA demonstrated an elevated risk for ovarian cancer, then a transvaginal ultrasound was performed. There was no reduction in mortality for average-risk women, and the program was not cost-effective. ${ }^{11,25,26}$ For high-risk women, there was a significant increase in the detection of earlystage ovarian cancer compared to historical controls as well as a low false positive rate, but the data are not sufficient to replace the current recommendation for high-risk women to undergo a risk-reducing salpingo-oophorectomy $(\mathrm{RRSO}){ }^{24}$

\subsubsection{Histological Subtypes}

Ovarian cancer is a heterogenous disease with different histologic subtypes. First, ovarian cancer types can be broken down by the cell from which it originates: epithelial (90\% of cases), sex-cord stromal, germ cell, and mixed-cell type. ${ }^{27}$ Epithelial ovarian cancer can be further broken down into multiple histological subtypes (Table 1). ${ }^{27-31}$ Information on the histological subtype is 
pivotal to understand relevant risk factors and best treatment approaches. The WHO classifies ovarian tumors into one of two types. Type I tumors notably include low-grade serous, endometrioid, clear cell, and mucinous carcinomas; these tumors are typically low grade and have a slow progression. Rarely, type I tumors can be malignant Brenner or seromucinous. Somatic variants in these tumors typically involve $K R A S$ and $B R A F .{ }^{27}$ The type II category encompasses high-grade serous carcinomas, carcinosarcomas, and undifferentiated carcinomas. These tumors often progress rapidly and aggressively, and they are likely to carry somatic variants in TP53 as well as somatic or germline variants in BRCA1/2.,27,32

Table 1 Distribution of histological subtype of invasive epitheical ovarian carcinomas

\begin{tabular}{c|c|c}
\hline Type & Histological Subtype & Estimated Prevalence \\
\hline \multirow{4}{*}{ I } & Low-grade serous & $3.5 \%$ \\
\cline { 2 - 3 } & Endometroid & $11 \%$ \\
\cline { 2 - 3 } & Clear cell & $12 \%$ \\
\cline { 2 - 3 } & Mucinous & $3.5 \%$ \\
\cline { 2 - 3 } & Other & $2 \%$ \\
\hline II & High-grade serous & $68 \%$ \\
\hline & Other & Rare \\
\hline
\end{tabular}

\subsubsection{Risk and protective factors for epithelial ovarian cancer}

For a woman living in the United States, the average lifetime risk of developing epithelial ovarian cancer is $1-2 \% .33,34$ However, there are several factors that are known to increase or decrease the risk of EOC. Li et al. (2015) created an epidemiologic risk prediction model using data from 202,206 Western European women. Although this model has never been validated, it does provide insight into potential risk and protective factors, many of which have been supported by other studies. ${ }^{35}$ Certain factors have only been shown to have an association with particular 
histological subtypes, which emphasizes the importance of understanding the etiology of ovarian cancer subtypes (Table 2).

Table 2 Risk and protective factors for invasive epithelial ovarian cancer

\begin{tabular}{|c|c|c|}
\hline Evidence Level & Risk Factor & Protective Factor \\
\hline Strong & $\begin{array}{l}\text { Family history of ovarian cancer }{ }^{34,36} \\
\text { Hormone replacement therapy } \\
\text { Endometriosis (clear-cell, low-grade } \\
\text { serous, endometroid) } \\
\text { Increasing height } \\
\text { Higher BMI }\end{array}$ & $\begin{array}{l}\text { Parity } \\
\text { Oral contraceptive use } \\
\text { Tubal ligation }^{42,40,41} \\
\text { Bilateral salpingo- } \\
\text { oophorectomy }^{43,44}\end{array}$ \\
\hline Moderate & $\begin{array}{l}\text { Older age at menopause } e^{35,45} \\
\text { Younger age at menarche } \\
\text { Diabetes mellitus } \\
\text { S6 } \\
\text { Smoking (mucinous) } \\
\text { Genital powder }^{47}\end{array}$ & $\begin{array}{l}\text { Older age at last birth }{ }^{49} \\
\text { Breastfeeding }{ }^{45,50}\end{array}$ \\
\hline Insufficient & $\begin{array}{l}\text { Incomplete pregnancy }{ }^{51-53} \text {, } \\
\text { infertility drugs }{ }^{54,55}, \text { polycystic } \\
\text { ovary syndrome (PCOS) })^{56} \text {, pelvic } \\
\text { inflammatory disease (PID) })^{57}, \\
\text { alcohol }^{58}\end{array}$ & Multiple births ${ }^{59}$, hysterectomy ${ }^{43,45}$ \\
\hline
\end{tabular}

For family history, the increase in risk for EOC depends on the degree of relation to the affected family member, as well as the number of family members affected. A woman with an affected first degree relative is about three times more likely to develop ovarian cancer than a woman without this family history. ${ }^{34,36}$ If a woman has more than one affected first-degree relative, she is 10 times more likely to develop ovarian cancer. ${ }^{60} \mathrm{BRCAl/2}$ pathogenic variants are estimated to account for a quarter of the familial relative risk for first-degree relatives. Other factors that increase familial relative risk include having affected relatives with EOC diagnosed under 50 years old and affected relatives with serous histology. ${ }^{36,60}$ 
Surgical removal of the ovaries is currently recommended for women at an increased risk of ovarian cancer because it is the strongest protective factor. ${ }^{4}$ RSSO has been shown to dramatically reduce the risk of ovarian cancer in multiple studies, with risk reduction estimates around $80 \%{ }^{43,44}$ Oral contraceptive use is also an established protective factor. A meta-analysis that combined results from 45 epidemiological studies found that the use of oral contraceptives reduces a woman's risk for ovarian cancer by $27 \%$ compared to women who reported never using them. Moreover, the longer the duration of use, the lower her risk; taking oral contraceptives for at least five years reduces the risk of developing ovarian cancer by approximately $50 \%{ }^{41}$ Further research is still needed to clarify risk estimates with knowledge of genetic predispositions and establish more evidence for factors that are currently not well supported.

\subsection{Genetic Predispositions to Ovarian Cancer}

Several genes have been identified to be associated with an increased susceptibility to EOC. ${ }^{61-65}$ It is currently estimated that about $20-25 \%$ of ovarian cancer is due to a hereditary predisposition. ${ }^{2,66} B R C A 1$ and $B R C A 2$ pathogenic variants account for the majority of hereditary ovarian carcinomas, followed by pathogenic variants related to Lynch syndrome. ${ }^{3,9,61,62,66}$ Other genes have been shown to contribute moderately to EOC risk such as RAD5ID, RAD5IC, BRIPI, $B A R D 1$, and $P A L B 2$, among others. ${ }^{63,64}$ Germline genetic testing can identify unaffected individuals who would benefit from preventative strategies; it can also help to direct treatment, inform prognosis, and elucidate additional beneficial screening for affected individuals. Current NCCN guidelines recommend that any woman with a diagnosis of epithelial ovarian, fallopian tube, and/or peritoneal cancers be offered germline genetic testing. ${ }^{7}$ 


\subsubsection{BRCA1 and BRCA2}

Both $B R C A 1$ and $B R C A 2$ are associated with the autosomal dominant Hereditary Breast and Ovarian Cancer (HBOC) syndrome. These genes are necessary for double-stranded DNA breaks to be repaired by homologous recombination. ${ }^{61}$ Several studies have aimed to quantify the frequency of $B R C A 1 / 2$ germline pathogenic variants in women with ovarian cancer. A case-control study in Australia with 1,001 women found germline BRCAl/2 pathogenic variants in $14.1 \%$ of patients with non-mucinous ovarian carcinomas. When only looking at patients with high-grade serous histology, this prevalence increased to $22.6 \% .{ }^{61}$ A prospective cohort study of 104 patients with EOC found that $21.15 \%$ of patients carried $B R C A 1 / 2$ pathogenic variants, and patients with high-grade serous histology had a higher prevalence $(25.7 \%)$ of these variants. ${ }^{67}$ One study specifically sought to estimate the prevalence of $B R C A 1 / 2$ variants in an ethnically diverse sample of 585 patients with EOC and found that $22.5 \%$ carried a pathogenic variant, again with a higher prevalence (27.6\%) in those with a serous histology ${ }^{68}$ Importantly, not all patients identified to have a pathogenic variant in BRCAl/2 had a reported family history of breast or ovarian cancer. $44 \%$ of patients in the Australia study had no suggestive family history at all. ${ }^{61}$ This study, and many others, are consistently finding that family history is not sufficient to predict pathogenic variant status; this supports current $\mathrm{NCCN}$ guidelines to offer genetic testing to any woman with epithelial ovarian cancer, regardless of family history. $3,7,61,62,66-69$

For the general population, the lifetime risk of ovarian cancer is only 1-2\% with an average age of diagnosis of 63 years old..$^{22,33,34}$ In the largest prospective cohort study to date, researchers estimated age-specific risks for breast, ovarian, and contralateral breast cancer in BRCA1/2 pathogenic variant carriers. The cumulative lifetime risk (to age 80 ) of ovarian cancer for a $B R C A I$ carrier was $44 \%$, while for $B R C A 2$ it is around $17 \% .^{70}$ The average age of diagnosis for ovarian 
cancer also differs between the two genes, with $B R C A l$ pathogenic variant carriers typically being diagnosed at younger ages ${ }^{66-68,70} B R C A 1$ carriers have a median age of diagnosis of ovarian cancer of 54 years compared to approximately 60 years for $B R C A 2 .{ }^{70}$ Importantly, other cancer risks exist for $B R C A 1 / 2$ pathogenic variant carriers. Perhaps most notable is the lifetime breast cancer risk, which can be as high as $87 \%$; other associated cancers include male breast, prostate, pancreatic, and melanoma. ${ }^{14}$ The benefit of identifying $B R C A 1 / 2$ germline pathogenic variants is thus apparent, as surveillance and risk-reducing strategies could detect cancer at earlier stages or decrease the risk of developing many of these cancers.

\subsubsection{Mismatch repair genes}

Germline pathogenic variants in certain mismatch repair (MMR) genes-MLH1, PMS2, MSH2, and MSH6 - and EPCAM are associated with Lynch syndrome, another autosomal dominant cancer predisposition syndrome. While the main cancer risks are colorectal and endometrial, there is an increased risk of ovarian cancer as well, along with skin, gastric, bile duct, small bowel, and pancreatic cancers. ${ }^{13,71}$ One study that sequenced germline DNA from 1,915 women with ovarian cancer found that $0.4 \%$ of ovarian cancer patients had pathogenic variants in MMR genes. ${ }^{72}$ The lifetime risk of ovarian cancer depends on the specific MMR gene that is mutated. MLH1 and $M S H 2$ have been shown to have higher lifetime risks than MSH6 and $P M S 2 .{ }^{13,71}$ In a recent multicenter prospective observational study, the cumulative incidence of ovarian cancer was $11 \%$ for $M L H 1$ pathogenic variant carriers, $17.4 \%$ for $M S H 2,10.8 \%$ for $M S H 6$, and $3 \%$ for $P M S 2 .{ }^{13}$

Ovarian cancer is typically diagnosed between ages 42 and 49 for patients with Lynch syndrome. ${ }^{9,71,73,74}$ One study that examined data on more than 800 women from a Lynch syndrome 
registry and cohort study calculated a median age of onset of 46 years for ovarian cancer; the range of age of onset was wide, with the youngest woman being 20 years old and the oldest being $75 .{ }^{9}$ Tumor histology is most often endometroid, although serous carcinomas are also associated with Lynch syndrome. ${ }^{9,73,74}$ The survival rate of ovarian cancers related to Lynch syndrome is highlikely in part due to the difference in tumor histology characteristics — with studies finding a 10year survival of $84-87 \% \cdot{ }^{13,73}$

\subsubsection{Other genes}

Pathogenic variants in other genes involved in homologous recombination have been identified to increase a woman's risk of EOC. Recently identified genes include $R A D 51 C$, RAD51D, BRIP1, and PALB2. ${ }^{63,64,75-77}$ One study examined pedigrees from 480 families with a history of breast and ovarian cancer that had negative BRCA1/2 testing results. The researchers found that $1.3 \%$ of families had a pathogenic variant in $R A D 51 C$ segregating with disease. ${ }^{76}$ Another study examined 911 BRCA1/2-negative families with breast and ovarian cancer and found that $0.9 \%$ carried pathogenic variants in $R A D 51 D$. The relative risk of ovarian cancer for pathogenic variant carriers was estimated to be 6.3 times population risk, while the relative risk for breast cancer was 1.3 and not statistically significant. ${ }^{75}$ Pathogenic variants in BRIP1 increase risk mainly for high-grade serous EOC, although the specific risk is not currently well-understood. Older ages of diagnosis are also associated with BRIP1 pathogenic variants. ${ }^{63}$ One study found that certain frameshift BRIPI pathogenic variants significantly increased the risk for ovarian cancer, while more common missense variants were not associated with increased risk. ${ }^{77}$ Finally, $P A L B 2$ pathogenic variants are known to confer breast cancer susceptibility, but more studies are 
finding that ovarian cancer risk may be increased as well. Further research is needed to better determine the estimated ovarian cancer risk associated with pathogenic variants in this gene. ${ }^{63,65}$ Massively parallel sequencing has identified other potential ovarian cancer susceptibility genes, but more studies are needed to fully understand their penetrance and risks. One study utilized this sequencing technology with 360 women with ovarian, fallopian tube, or peritoneal cancers and found germline pathogenic variants in $23 \%$ of them. $18 \%$ of pathogenic variants were in BRCA1/2, and the other 6\% were in MSH6, RAD51C, BRIP1, PALB2, TP53, BARD1, CHEK2, MRE11A, NBN, and RAD50. At the time of this study, RAD51D had not been implicated in ovarian cancer predisposition and was therefore not included. All genes identified, with the exception of MSH6 and TP53, are involved in the homologous recombination pathway. Importantly, the women with MSH6 and TP53 germline pathogenic variants did not meet criteria for Lynch syndrome or Li-Fraumeni syndrome, respectively. $30 \%$ of women in the study had no family history of breast or ovarian cancer, again pointing to the need for testing without such a history. ${ }^{3}$

\subsection{Ovarian Cancer Genetic Testing}

In the field of cancer, genetic testing can be ordered for a variety of reasons. Regardless of whether an individual is affected, genetic testing can increase knowledge about personal and family cancer risks. It can provide an explanation for a personal or family history of cancer if a genetic pathogenic variant is found. For affected individuals, genetic testing can result in personalized treatment. Unaffected persons may benefit from enhanced surveillance or options for risk reduction. Sometimes, genetic testing can provide reassurance that there is likely not a singlegene predisposition to cancer in the family. 


\subsubsection{Utility of ovarian cancer genetic testing}

For patients with ovarian cancer, genetic testing can inform prognosis and guide

treatment. ${ }^{8,78-80}$ Tumor testing alone can provide this information, but given the high frequency of germline pathogenic variants in patients with EOC, it does not provide all needed information. Germline results must be delineated in addition to somatic results to provide the patient and their family with the most comprehensive medical information. BRCA1/2 testing was historically more commonly used, but with the advent of next-generation sequencing, multi-gene panel testing has become both feasible and necessary and has been utilized more frequently in recent years. ${ }^{17,81}$

\subsubsection{BRCA1/2: Management and Screening}

Primary treatment of ovarian cancer is typically platinum chemotherapy and surgery to remove the tumor, followed by maintenance therapy. ${ }^{7}$ A study comparing ovarian cancer outcomes in carriers of $B R C A 1 / 2$ pathogenic variants with non-carriers found an improved prognosis and a better response to platinum-based chemotherapy. ${ }^{80}$ The presence or absence of a $B R C A 1 / 2$ pathogenic variant guides the selection of and provides information on the magnitude of benefit of maintenance therapy as well. ${ }^{7}$ Maintenance therapy is typically achieved through poly ADP-ribose polymerase (PARP) inhibitors, which prevent cancer cells from repairing their damaged DNA and can help to trigger apoptosis. Until recently, PARP inhibitors were only recommended for metastatic treatment of homologous recombination (HR) deficient tumors-such as a $B R C A 1 / 2$ mutated tumor - after at least three other lines of therapeutic therapy had been utilized. ${ }^{78}$ The PARP inhibitor Niraparib is now FDA-approved as first-line maintenance therapy after response to platinum-based chemotherapy for late-stage ovarian cancer, regardless of the HR status of the tumor. It is important to note, however, that the response to Niraparib was significantly better for 
HR deficient tumors. For example, in the clinical trial, the median progression-free survival was 21.9 months for HR deficient tumors compared to 13.8 months in the overall population; this value for the placebo group was 10.4 months. ${ }^{8}$ Knowledge of $B R C A 1 / 2$ tumor status is therefore essential for treatment and prognosis purposes.

As mentioned previously, tumor testing alone is not sufficient due to the high prevalence of germline pathogenic variants in patients with ovarian cancer. ${ }^{67}$ Identifying somatic mutations in the tumor provides information for treatment of the tumor only; identifying germline mutations present in the entire body provides information for screening and risk reduction of all cancers associated with the mutation. Unaffected relatives also greatly benefit from genetic testing for ovarian cancer susceptibility genes. If a pathogenic variant is identified in an affected relative, cascade testing permits the testing of blood relatives for the same variant to identify those at increased risk for EOC. As there are currently no effective screening methods, the main benefit of genetic testing lies in risk reduction. ${ }^{12,24}$ For women with pathogenic variants in BRCA1/2 who are unaffected with ovarian cancer, it is recommended that they undergo a risk-reducing salpingooophorectomy once childbearing is completed, ideally between the ages of 35-40 for BRCAl and between the ages of $40-45$ for $B R C A 2$. If there is an ovarian cancer diagnosis in the family prior to the recommended age for RRSO, then earlier prophylactic surgery should be discussed. ${ }^{4}$ Although this procedure significantly reduces the risk of ovarian cancer, and possibly breast cancer, it does incur some risks associated with early menopause, such as osteoporosis and heart disease. $^{82,83}$

There are guidelines in place for the additional cancer risks associated with $B R C A 1 / 2$ pathogenic variants as well. Note that while these recommendations are standard, they may or may not be indicated in patients with EOC, depending on their clinical picture. Breast cancer screening 
begins at age 25 with an annual MRI. Beginning at age 30, a mammogram should occur annually with the MRI. The option of a risk-reducing bilateral mastectomy should be discussed. Pancreatic screening may also be justified, although data for its efficacy are limited. ${ }^{4}$ The American Gastroenterological Association currently recommends screening in individuals with pathogenic variants in $B R C A 1 / 2$ only if there is a first degree relative with pancreatic cancer. ${ }^{84}$

\subsubsection{Mismatch repair genes: Management and Screening}

Women diagnosed ovarian cancer who have mismatch repair deficient (dMMR) tumors may have tailored therapy options. While there are not as many targeted therapy options for nonBRCA1/2 pathogenic variants in ovarian cancer tumors, a growing body of evidence is suggesting that targeted therapy is warranted for dMMR tumors. ${ }^{85}$ Pembrolizumab is a specific immunotherapy, for example, that has been shown to have increased efficacy in dMMR ovarian cancer tumors. There are numerous clinical trials available for patients with dMMR tumors, and thus targeted therapies will likely become more widely available in the future. Patients with dMMR tumors have also been shown to have improved survival, making it a useful marker for prognosis. ${ }^{9}$ For unaffected women with pathogenic variants in $M L H 1$ and $M S H 2$, risk-reducing RRSO is recommended; for individuals with pathogenic variants in PMS2, EPCAM, or MSH6, there is currently insufficient evidence to recommend RRSO ${ }^{86}$

There are additional screening and management guidelines for germline MMR pathogenic variants, which may or may not be applicable to individuals affected with ovarian cancer. The two largest risks and most well-defined screening guidelines are for colon and endometrial cancer. ${ }^{13}$ For men and women, colonoscopies should begin between the ages of 20 and 25 (or 2-5 years prior to the earliest colon cancer in the family, if earlier) and should be repeated every 1-2 years. ${ }^{86}$ Daily aspirin use has been shown to reduce colorectal cancer risk, although more data is needed in order 
to determine an optimal dosage and duration of use ${ }^{87}$ Pancreatic cancer screening is recommended only if an individual has an affected first-degree relative. ${ }^{84}$ Many women affected with ovarian cancer have a total abdominal hysterectomy in addition to oophorectomy, and thus have reduced their endometrial cancer risk by as much as possible. Unaffected women should be educated on symptoms of endometrial cancer. Screening via endometrial biopsy every 1-2 years can be considered starting at age 30-35. A risk-reducing hysterectomy can be considered as well. ${ }^{86}$

\subsubsection{Other genes: Management and Screening}

Other moderate-risk pathogenic variants as previously described warrant additional screening, although guidelines are generally not as well-established. Affected women with pathogenic variants that result in homologous recombination deficiency have an improved response to maintenance therapy with PARP inhibitors. ${ }^{4,7}$ Clinical trials or other targeted therapies may become available for other genes and should be investigated when genetic test results are available. For unaffected women, RRSO should be considered between age 40-45 for women with a pathogenic variant in $B R I P 1$ and 45-50 for $R A D 51 C / D$, or earlier if family history of early-onset ovarian cancer is present. Further studies are needed to establish whether or not RRSO is warranted for other moderate-risk genes. Women with a pathogenic variant in PALB2 can consider RSSO after menopause if there is a family history of ovarian cancer. They should begin annual breast mammograms with MRI at age 30 and should discuss the option of a bilateral risk-reducing mastectomy. For other genes, breast cancer surveillance should be based on family history. ${ }^{4}$ 


\subsubsection{Factors that Influence Genetic Testing Decisions}

There are several factors that may predict whether a person decides to undergo genetic testing, but there is inconsistency from study to study regarding which factors are significant. ${ }^{88}$ Some of these factors have changed as genetic testing methods and anti-discrimination laws have been updated. In older studies, predictors of $B R C A 1 / 2$ genetic testing uptake included being Caucasian, older, and wealthier as well as having children, a family history of breast or ovarian cancer, and a higher level of knowledge about genetic testing. ${ }^{89-91}$ One study from 2011 noted that the ability to cure or reduce the risk of a disorder also appeared to be a strong predictor of genetic testing; $77 \%$ of individuals were theoretically willing to undergo testing for a curable condition, while only $50 \%$ of individuals were interested in testing for an incurable disorder. ${ }^{92}$ Studies within the past ten years have conflicting evidence as to whether or not age, race, and education level are predictors of genetic testing. However, relatively consistent predictors of testing uptake include having a personal or family history of cancer, having a higher income, being more knowledgeable about genetics, and perceiving more benefits to the test than risks. ${ }^{88,93-95}$ A recent study also found that having discussed genetic testing with a surgeon was a strong predictor of genetic testing in newly diagnosed breast cancer patients. ${ }^{96}$

Several studies have attempted to elucidate specific reasons why unaffected individuals decline genetic testing. One study looking only at genetic testing for BRCAl in unaffected individuals from HBOC families noted that individuals were more likely to request testing if they had a higher socioeconomic status and adequate health insurance. This study took place in 1996, prior to the passing of the Genetic Information Non-Discrimination Act (GINA), so many individuals cited a fear of discrimination from employers or health insurance as the reason they declined testing. ${ }^{91}$ Another study from 2003 with 13 women at risk of carrying a pathogenic variant 
in $B R C A 1 / 2$ found that being satisfied with participating in a surveillance program and being emotionally unprepared to cope with testing results were also reasons that testing was declined. Additionally, women who had a higher reluctance toward undergoing prophylactic surgery were less likely to move forward with genetic testing compared to women who were more comfortable with surgical intervention. ${ }^{97}$ Newer studies highlight additional reasons why patients opt out of genetic testing, including distrust in genetic information, perception of more risks than benefits, and significant financial barriers. ${ }^{98,99}$ One retrospective chart review from 2018 found that 267 of 1082 individuals who met NCCN criteria for $B R C A 1 / 2$ analysis did not receive genetic testing. However, only $22 \%$ of these individuals were disinterested in testing. $40 \%$ were advised to gather additional information from relatives before testing, and 38\% desired testing but were prohibited by the cost. ${ }^{98}$

In all aspects of medical care, health literacy plays an important role; this is the ability of a person to get the health-related information they need, understand it, and utilize it appropriately to make medical decisions. All health care professionals have a vital role in understanding how health literacy influences the care that patients receive. When it comes to genetic testing, limited health literacy has been consistently shown to be associated with lower genetic health knowledge. One study examined how genetic health literacy plays a role in understanding genetic testing; the results indicated that patients' understanding of the utility of genetic testing is positively correlated with genetic health literacy. ${ }^{100}$ Another study interestingly noted that patients with low health literacy had a greater perceived importance of genetic information but a lower perceived importance of family health history information, suggesting a disconnect in their understanding of genetics and genetic testing. ${ }^{101}$ It is therefore essential that health care providers be aware of their 
patient's level of health literacy in order to appropriately communicate information and create equitable health care for all patients.

\subsubsection{Psychological Impact of Genetic Testing Results}

Previous studies have generally shown favorable psychosocial outcomes after genetic testing, with a slight increase in anxiety immediately after results are disclosed, followed by a return to pre-testing anxiety levels. ${ }^{102,103} \mathrm{~A}$ comprehensive review by Hirschberg et al. found that both men and women who receive genetic testing for hereditary cancer syndromes experience no clinically significant long-term distress. Any psychological distress that does arise during the testing process appears to decrease over the course of the first year after testing. Individuals tested positive for a pathogenic variant in a cancer predisposition gene who continue to have higher levels of distress after testing tend to have a higher level of baseline distress, a history of depression and/or psychotropic drug use, an elevated risk perception, complicated grief or unresolved loss, especially if they lost a relative due to hereditary cancer. Additionally, individuals with children were more likely to have long-term distress. ${ }^{104}$ Being aware of these risk factors can facilitate the counseling process and can better prepare patients for their testing results.

\subsection{Alternative Service Delivery Models}

The growing demand for genetics services, combined with the deficit in genetics health care professionals, has led to a call for alternative service delivery models. ${ }^{15,105}$ The most recent practice analysis conducted by the American Board of Genetic Counselors (ABGC) found that 
only $77.3 \%$ of certified genetic counselors are currently working in clinic, and $40.6 \%$ are working in cancer. ${ }^{106}$ More studies are necessary to clarify how many cancer genetic counselors are needed to meet current demand. Geographical barriers are a major access concern; a study in California found that genetics providers are concentrated in major metropolitan areas, and on average patients travel approximately 80 miles to access these services. ${ }^{15}$ To increase patient access, many cancer genetics providers have incorporated alternative service delivery models into their practice such as telephone, telemedicine, pre-recorded videos, or group genetic counseling. These models mitigate issues with travel distance and are generally more convenient for both the counselor and the patients, but issues with billing or reimbursement, equipment setup, and internet access, as well as the inability to physically see the patient hinder some efforts. ${ }^{107}$

Studies have shown that alternative care delivery models result in an increase in genetics knowledge and access to services, although the effects on risk perception and possible lingering misconceptions warrant further study. ${ }^{108-111}$ The Cancer Risk Education Intervention Tool (CREdIT) was designed to facilitate pre-counseling education for low literacy women who are at an increased risk for breast and ovarian cancer. Participants' general genetics knowledge improved after viewing the CREdIT slides, but changes in risk perception varied between participantssometimes inappropriately increasing or decreasing. Additionally, some misconceptions remained after viewing the content; one woman still thought that she inherited her cancer predisposition from her niece, for example. ${ }^{109}$

\subsubsection{Cancer Genetic Testing by Non-Genetic Health Professionals}

With the increase in interest in genetics services, many non-genetic health professionals (NGHPs) are ordering genetic testing themselves instead of referring patients to a genetics 
provider. A recent survey investigating the attitudes, knowledge, and skills of NGHPs with regards to hereditary cancer testing found that these providers generally have positive views about their communication skills and are confident in their ability to take a family history and order genetic testing. The majority of providers responded that they discussed the benefits and limitations of close cancer surveillance (95\%) and prophylactic surgery (89\%), discussing results with family members (91\%), and confidentiality (89\%). Importantly, however, only $71 \%$ of providers thought it was their responsibility to manage emotions; $68 \%$ felt confident in their ability to interpret variants, and 55\% had received formal training on communicating hereditary information. ${ }^{112}$ Other studies have noted that an increase in knowledge corresponds to an increase in the confidence of the provider to deliver genetics services, and many providers asked for more formal training in genetics. ${ }^{113-115}$ A study by the American Society of Breast Surgeons found that the majority of breast surgeons provided genetic testing and counseling, created 3-generation pedigrees and provided pre- and post-test counseling. Still, $11.8 \%$ of respondents did not feel confident in their ability to provide counseling and desired more educational support in genetics. ${ }^{114}$ It thus appears that NGHPs are willing and eager to provide genetics services, but more educational opportunities to increase their knowledge of genetics may be necessary to improve confidence in all aspects of the genetic testing process.

\subsubsection{Knowledge Gaps and Educational Needs}

One method to mitigate this issue is to provide more formal education in topics related to hereditary cancer genetics and genetic testing so that providers can better understand this process and identify which patients require a referral. A plethora of studies have examined the current level of genetics knowledge in NGHPs and the effects of educational programs. Genomic literacy and confidence appear to differ greatly between practice groups, provider specialty, and years of 
practice. For example, OB-GYNs and specialists (e.g. surgeons and oncologists) generally have greater genetics knowledge and confidence compared to primary care physicians. ${ }^{113,116,117}$ Common knowledge gaps include the inability to recognize paternal inheritance of HBOC, the need for comprehensive rearrangement testing in high-risk women, and appropriate testing options for a VUS result. ${ }^{118,119}$ One study surveyed providers in Florida who order BRCA1/2 testing and assessed the educational needs and preferences among this group; responses from mostly physicians and nurse practitioners indicated that in-person training was most strongly preferred. Minimal time off work and continuing education credits were also strong motivators to participate in formal education training. ${ }^{120}$ Other commonly reported preferred educational methods include multi-modal genetics courses that combine distance learning with interdisciplinary in-person training, seminars detailing clinical genetics services referral pathways, electronic referral guidelines, and example case scenarios. ${ }^{116,121,122}$ A study conducted by the City of Hope demonstrated that a targeted outreach program among community-based clinicians resulted in a $40 \%$ increase in cancer genetics knowledge on average. $77 \%$ of participants felt that they could use the course information and materials to better counsel and refer patients for hereditary cancer risk assessment. ${ }^{123}$ Various professional societies and academic institutions currently offer seminars, workshops, and web-based curriculum and resources to help educate providers. ${ }^{124}$

\subsubsection{Motivations for and barriers to cancer genetics referrals}

Although education programs aim to increase genetic literacy and knowledge, they are also intended to increase appropriate referrals to hereditary cancer genetics services. A survey of NGHPs indicated that common reasons for referral include eligibility based on the patient's personal or family history, the need for enhanced risk assessment, improved medical management, concern for family members, and patient request. Major barriers to referral included a lack of 
knowledge about a cancer genetics program and limited awareness of improved insurance coverage and anti-discrimination legislation. ${ }^{125}$ Another study that surveyed gastroenterologists and colorectal surgeons found that $82.7 \%$ had referred a patient to cancer genetic counseling. The majority of those surveyed were able to correctly identify which patients were at a "much higher" risk to develop colorectal cancer than the general population; fewer were able to identify those at "somewhat higher" risk than the general population. Risk categories were based off the American Gastroenterological Association's criteria for high, moderate, and average risk to develop colorectal cancer. The survey identified barriers to referral including insurance coverage issues and discrimination fears, as well as a lack of clear guidelines from professional organizations. Similar to previously mentioned studies, physicians were more confident ordering testing than interpreting the results or providing emotional support. ${ }^{126}$

\subsubsection{Adverse effects of incorrect testing and non-referrals}

Many studies illustrate the negative effects that occur when testing is ordered incorrectly, or when appropriate referrals are not made. A national case series examined patterns from 21 cases submitted to the National Society of Genetic Counselors Cancer Special Interest Group that exhibited adverse outcomes of testing by NGHPs. Major patterns noted were: the wrong genetic test was ordered (e.g. BRCA1/2 analysis instead of MMR genes or full-sequencing when a familial pathogenic variant was known), the results were mis-interpreted (e.g. a VUS was counseled as if pathogenic or incorrectly considering a patient to have a "true negative" result), and inadequate genetic counseling was given. ${ }^{127}$ Negative outcomes of errors in genetic testing and result interpretation include unnecessary prophylactic surgery, unnecessary testing, psychosocial

distress, false reassurance, and increased cost to insurance companies and patients. ${ }^{127,128}$ Provider education could lead to improved availability of services and more appropriate care. 


\subsubsection{Oncologist-Led Genetic Testing for Epithelial Ovarian Cancer Patients}

Data from the National Health Interview Survey (NHIS) and a recent study indicated that only a third of individuals with a history of ovarian cancer have undergone genetic testing, despite current NCCN guidelines that all these women should receive genetic testing. ${ }^{7,17,93}$ Only $15 \%$ of patients with ovarian cancer had even discussed genetic testing with a healthcare provider. ${ }^{93}$ An increase in public awareness, targeted at providers and women with ovarian cancer, may help to increase utilization of genetics services. ${ }^{90,93}$ Professional organizations like the American College of Obstetricians and Gynecologists (ACOG), American Society of Clinical Oncology (ASCO), and Society of Gynecologic Oncologists (SGO) have published recommendations and guidelines that support germline and somatic genetic testing for epithelial ovarian cancer patients at the time of diagnosis; they state informed consent is required, including a discussion of the benefits, limitations, and implications of genetic testing results. ${ }^{5,6,129,130}$ SGO specifically recommends that patients begin with genetic counseling to discuss testing options, but they also acknowledge that if these services are not available from a genetic counselor, it is appropriate to receive counseling from a provider trained in cancer genetic counseling. ${ }^{6}$

A streamlined $B R C A 1 / 2$ genetic testing pathway for ovarian cancer patients has been proposed and studied in recent years. Colombo et al. published the results of a study entitled Evaluating a Streamlined Onco-genetic BRCA Testing and Counseling Model Among Patients with Ovarian Cancer (ENGAGE). In this study, a clinical team of oncologists and oncology nurses received training on $B R C A 1 / 2$ testing and genetic counseling techniques. Pre-test counseling was provided by this team, although patients could elect to have counseling from a genetic counselor or geneticist prior to testing if desired. Results were disclosed by the clinical team, and patients with a positive result were recommended to undergo further genetic counseling with a genetic 
counselor or geneticist. The results of the study were favorable, with a median turnaround time of 4.1 weeks in the United States. Patient satisfaction was $99 \%$, and $80 \%$ of oncologists agreed that the process worked well and was efficient. However, only $50 \%$ of genetic counselors and geneticists agreed that patients received accurate $B R C A 1 / 2$ testing information in the pre-test counseling session, suggesting that the process still requires some fine-tuning. ${ }^{19}$

Barriers to implementing this type of streamlined pathway have been reported, including a limited number of providers that were appropriately trained, time constraints, insufficient health insurance, fear of discrimination, and issues with family communication. ${ }^{124,131}$ Issues that arise once the pathway has been implemented include difficulty interpreting a VUS result and lack of patient awareness of result implications for their own treatment. ${ }^{19,132}$ Pre-test counseling requires improvements to better educate patients, and referrals to a genetics provider are likely warranted for not only positive results, but also VUS results and a negative result for a patient with a family history. ${ }^{18}$ Still, other studies have shown comparable results with quick turnaround time, high patient satisfaction, high rates of genetic counseling appointment attendance, and appropriate changes in treatment based on genetic testing results. ${ }^{18,131,133,134}$ Patients were satisfied with the timing of testing and did not appear to be overwhelmed with the additional testing at the time of diagnosis. ${ }^{132}$ Thus, oncologist-led genetic testing for patients with EOC appears to be a feasible service model. 


\subsection{Manuscript}

\subsection{Background}

Every year, nearly 300,000 women receive a diagnosis of ovarian cancer across the world. As the $5^{\text {th }}$ leading cause of cancer death in women, the diagnosis is often devastating. ${ }^{20}$ Genetic predispositions to ovarian cancer have been identified and are thought to contribute to $20-25 \%$ of cases. $^{2}$ Hereditary Breast and Ovarian Cancer syndrome (HBOC), Lynch syndrome, and pathogenic variants in moderate-risk genes have all been demonstrated to increase a woman's lifetime risk of developing ovarian cancer. ${ }^{3,9,67,72}$

Due to the high frequency of germline pathogenic variants, current NCCN guidelines advise that all women diagnosed with epithelial ovarian cancer (EOC) be offered germline genetic testing. ${ }^{7}$ In spite of this, only about $35 \%$ of women with this diagnosis have undergone genetic testing. ${ }^{17}$ Knowledge of a germline pathogenic variant in an affected individual can inform prognosis, guide treatment, and clarify the need for management of other cancer risk. Studies show that women with $B R C A 1 / 2$ pathogenic variants have an improved prognosis and a better response to platinum-based chemotherapy and PARP inhibitors. ${ }^{8,78,80}$ These women may also benefit from additional cancer screening due to an increased risk of breast cancer, depending on their clinical status. ${ }^{14,70}$ Similarly, women with germline pathogenic variants in a Lynch-syndrome related gene have a higher survival rate, and some treatment options such as Pembrolizumab are targeted for

mismatch-repair deficient tumors. ${ }^{9,85}$ Surveillance with frequent colonoscopies and endometrial biopsies might also be indicated for colon and endometrial cancer risk management. ${ }^{13}$ 
Tumor testing alone can provide information to determine indications for targeted treatment options, but it cannot differentiate between germline and somatic variants. Identification of a germline pathogenic variant provides information on additional cancer risks, and it helps facilitate testing for at-risk family members. As such, tumor testing alone is not sufficient for women diagnosed with ovarian cancer. Germline genetic testing, or tumor testing followed by germline testing if there are results suspicious for a germline pathogenic variant, is necessary to provide comprehensive risk assessments to the patient and their families.

While the demand for genetic services has increased, there is a deficit in genetics health professionals. ${ }^{15,105}$ This has resulted in a call for alternative genetics service delivery models. Many non-genetics health professionals (NGHPs) are increasingly ordering genetic testing themselves, especially within the realm of hereditary cancer testing. Studies of oncologist-led testing pathways have been favorable so far, with quick turnaround times and high levels of patient and provider satisfaction. ${ }^{19,133,134}$ However, knowledge gaps and barriers to cancer genetics referrals after testing is completed persist and must be addressed for this service model to provide appropriate care. A recent study found that most NGHPs' self-reported proficiency discussing the benefits and limitations to close surveillance and risk-reducing surgery, importance of delineating information to family members, and confidentiality of results. However, only $68 \%$ felt confident in interpreting all variants, and $55 \%$ had never received formal training in communicating this information. ${ }^{112}$ This theme has been replicated in other studies, as the American Society of Breast Surgeons reported that most providers were ordering genetic testing and were counseling patients on results, but $11.8 \%$ of respondents did not feel confident in their counseling abilities and desired more educational support in genetics. ${ }^{114}$ Targeted outreach programs have been successful in the past in improving genetics knowledge, appropriate referrals, and counseling abilities. ${ }^{123}$ Errors in genetics 
service delivery can have severe negative outcomes including unnecessary prophylactic surgery, inappropriate testing, psychological distress, false reassurance, and increased cost to insurance companies and patients. ${ }^{127,128}$

The goal of this study was to evaluate the current genetic testing practices of oncology providers for patients with epithelial ovarian cancer. Data surrounding the genetic testing practices

of gynecologic oncologists are limited, and these individuals are central healthcare providers for women diagnosed with ovarian cancer. This study will help to elucidate how and when gynecologic oncologists are ordering genetic testing and referring patients to genetics services, and it could help highlight any barriers that currently exist. It will also assess provider confidence with different aspects of cancer genetics services to identify areas that may require educational outreach. Addressing these issues will facilitate access to genetic testing services for all patients with ovarian cancer and their families.

\subsection{Methods}

\subsubsection{Study Population}

A survey was sent to full and associate members of the Society of Gynecologic Oncology, a professional society comprised of gynecologic oncologists, researchers, medical oncologists, physician assistants, nurse practitioners, registered nurses, fellows, residents, students, patients, and caregivers. As healthcare systems differ vastly by country, only members who practice in the United States were recruited. Participants were deemed eligible if they are currently in clinical practice or have been in clinical practice within the past year. 


\subsubsection{Survey Development}

Prior to survey distribution, exempt IRB approval was obtained from the University of Pittsburgh (Appendix A). The survey was developed utilizing the Qualtrics Survey System, which was accessible through the University of Pittsburgh license. The survey collected information on participant demographics, genetic testing and referral practices, and confidence with different aspects of the genetic testing process (Appendix B). It was estimated to take approximately 15 minutes to complete. Demographic information recorded included current job title, primary area of medical practice, location (urban/suburban/rural), practice setting, years of experience, age, gender, and ethnicity. Genetic testing questions inquired about ordering frequency, timing, type of test (e.g., multi-gene panel vs. BRCAl/2 analysis only), barriers to testing, and how often results guide treatment decisions. Certain survey questions permitted multiple responses to be selected. Questions about referrals to genetics services similarly asked about frequency, timing, and barriers.

Several potential barriers to ordering genetic testing were asked in the survey, including patient disinterest, insurance coverage or discrimination concerns, lack of effect on medical management, lack of necessity, and confusion. A list of barriers to making cancer genetics referrals was provided for the respondents to select from, including patient disinterest, services already provided, insurance coverage or discrimination concerns, burden of additional appointments, lack of services in region, and confusion or lack of knowledge about services. Finally, a group of questions asked about education or training in genetics and confidence in: taking a 3-generation family history, ordering genetic testing, interpreting all possible results, counseling a patient on the meaning of the result, and deciding which patients should be referred to cancer genetics services. Respondents completed the survey online. Due to time constraints, the survey was not piloted. 


\subsubsection{Recruitment and Survey Distribution}

An e-mail was sent out to invite members of SGO to participate in the research survey on December $14^{\text {th }}, 2020$. The recruitment e-mail explained the goals of the study, pointed out potential risks and benefits to taking the survey, provided researcher contact information, and had a link to the survey (Appendix C). The survey was open for a total of six weeks and closed on January $22^{\text {nd }}$, 2021. Two reminder e-mails were sent out with two weeks and one week remaining. An informed consent paragraph appeared before any survey questions could be viewed and required the participant to acknowledge to continue (Appendix B). Survey completion was used as proof of informed consent. Respondents that completed less than half the questions were not included, as not all questions necessary for analysis were answered (i.e., missing information on frequency of referrals, provider confidence, and demographic information).

\subsubsection{Data Analysis}

Descriptive statistics were performed and bar graph data visualizations were created using Qualtrics for demographic information, testing and referral practices and barriers, and provider confidence. Cross tabulations were calculated between provider testing practice and both use of genetic testing results to guide treatment and frequency of referrals made. Statistical analysis was performed using STATA statistical software. Fisher's exact test was utilized to determine if there was a significant association between provider testing practice and confidence levels with different aspects of cancer genetics services and referrals. P-values were considered significant if they were less than 0.05. All outputs from statistical analysis can be found in Appendix D. 


\subsection{Results}

\subsubsection{Demographic Information}

The survey was sent to 1,444 members of SGO who are full or associate members currently residing in the United States. A total of 186 responses were received, therefore giving the study a $12.9 \%$ response rate. Twelve responses were excluded because less than half of the questions were answered. Four additional responses from individuals who are not currently in clinical practice were also excluded. Hence, 170 responses were included in the analysis.

Almost $82 \%$ of respondents were gynecologist oncologists (Table 3), and nurse practitioners comprised the next largest group (10.6\%). Thirty-three percent of respondents had 10-19 years of experience in patient care. Approximately 25\% of respondents had 0-9 years of experience, and another $25 \%$ had 20-29 years. $17 \%$ of respondents had 30 or more years of experience. The majority (95.3\%) of respondents worked primarily in gynecology/obstetrics or gynecologic oncology. Most respondents were white (84.7\%), non-Hispanic (94.1\%), and between the ages 30-69 (97.1\%), and slightly more respondents were female $(63.5 \%)$ than male. Individuals were asked two questions about practice type and location. Note that total percentages can be higher than 100 due to the ability to select multiple responses. The majority of respondents (53.5\%) worked at an academic center at least some of the time and 36.5\% of respondents were hospital based. More individuals reported to be part of a group practice (20\%) than a private practice (8.8\%). Most respondents worked in an urban setting (66.5\%) at least some of the time, followed by suburban (40.6\%) and then rural (7.1\%). Individuals that selected "Other" specified working at referral centers and in the military (Table 3). Patients with epithelial ovarian cancer made up less than half of all patients seen in clinical practice for $90 \%$ of providers. 
Table 3. Respondent Demographic Information

\begin{tabular}{|c|c|}
\hline Current job title & $\%(n)$ \\
\hline Gynecologic oncologist & $81.8 \%(139)$ \\
\hline Medical oncologist & $2.4 \%(4)$ \\
\hline Surgical oncologist & $0 \%(0)$ \\
\hline Nurse practitioner & $10.6 \%(18)$ \\
\hline Physician assistant & $3.5 \%(6)$ \\
\hline Registered nurse & $0.6 \%(1)$ \\
\hline Other & $1.2 \%(2)$ \\
\hline \multicolumn{2}{|l|}{ Years of experience in patient care } \\
\hline $0-9$ & $27.1 \%(46)$ \\
\hline $10-19$ & $33.5 \%(57)$ \\
\hline $20-29$ & $22.4 \%(38)$ \\
\hline 30 or more & $17.1 \%(29)$ \\
\hline \multicolumn{2}{|l|}{ Primary area of medical practice } \\
\hline Gynecology/obstetrics & $60.6 \%(103)$ \\
\hline Other (Gynecologic Oncology) & $34.7 \%(59)$ \\
\hline Internal medicine & $0.6 \%(1)$ \\
\hline Family practice & $0 \%(0)$ \\
\hline Other & $3.5 \%(6)$ \\
\hline \multicolumn{2}{|l|}{ Age } \\
\hline 29 or younger & $0.6 \%(1)$ \\
\hline $30-49$ & $57.1 \%(97)$ \\
\hline $50-69$ & $40.0 \%(68)$ \\
\hline 70 years or older & $2.4 \%(4)$ \\
\hline \multicolumn{2}{|l|}{ Gender } \\
\hline Female & $63.5 \%(108)$ \\
\hline Male & $36.5 \%(62)$ \\
\hline \multicolumn{2}{|l|}{ Ethnicity (select all that apply) } \\
\hline American Indian or Alaskan Native & $0 \%(0)$ \\
\hline Asian & $6.5 \%(11)$ \\
\hline Black or African-American & $5.3 \%(9)$ \\
\hline White & $84.7 \%(144)$ \\
\hline Other & $1.8 \%(3)$ \\
\hline \multicolumn{2}{|l|}{ Hispanic, LatinX, or Spanish origin } \\
\hline Yes & $2.9 \%(5)$ \\
\hline No & $94.1 \%(160)$ \\
\hline \multicolumn{2}{|l|}{ Location (select all that apply) } \\
\hline Rural & $7.1 \%(12)$ \\
\hline Suburban & $40.6 \%(69)$ \\
\hline Urban & $66.5 \%(113)$ \\
\hline Other & $3.5 \%(6)$ \\
\hline \multicolumn{2}{|l|}{ Practice setting (select all that apply) } \\
\hline Private practice & $8.8 \%(15)$ \\
\hline Group practice & $20.0 \%(34)$ \\
\hline Hospital based & $36.5 \%(62)$ \\
\hline Academic center & $53.5 \%(91)$ \\
\hline
\end{tabular}




\subsubsection{Ordering, Treatment, and Referral Practices}

The majority (85\%) of respondents always ordered genetic testing for patients with EOC (Table 4). The frequency that providers used genetic testing results to guide treatment and referred patients to cancer genetics was examined separately based on how often they ordered genetic testing. Of providers who always ordered genetic testing, about $30 \%$ also always used genetic testing results to guide treatment. $60 \%$ of these providers always referred patients to cancer genetics services. Of providers who often or sometimes ordered genetic testing, 23.8\% always used the results to guide treatment, and a third always referred patients to cancer genetics. Only four providers responded that they never ordered their own genetic testing; all of these individuals always referred patients to cancer genetics.

Table 4. Treatment and Referral Tendencies by Testing Practice

\begin{tabular}{|c|c|c|c|}
\hline & $\begin{array}{l}\text { I always ordered } \\
\text { genetic testing } \\
85.3 \%(145) \\
\end{array}$ & $\begin{array}{c}\text { I often/sometimes } \\
\text { ordered genetic testing } \\
12.4 \%(21) \\
\end{array}$ & $\begin{array}{c}\text { I never ordered } \\
\text { genetic testing } \\
2.3 \%(4) \\
\end{array}$ \\
\hline \multicolumn{4}{|c|}{ Used results to guide treatment } \\
\hline Always & $\begin{array}{c}29.7 \% \\
(43)\end{array}$ & $\begin{array}{c}23.8 \% \\
(5)\end{array}$ & $\begin{array}{c}50.0 \% \\
(2)\end{array}$ \\
\hline Often/Sometimes & $\begin{array}{c}69.7 \% \\
(101)\end{array}$ & $\begin{array}{c}76.2 \% \\
(16)\end{array}$ & $\begin{array}{c}50.0 \% \\
(2)\end{array}$ \\
\hline Never/Unsure & $\begin{array}{l}0.6 \% \\
\text { (1) }\end{array}$ & $\begin{array}{l}0 \% \\
(0)\end{array}$ & $\begin{array}{l}0 \% \\
(0)\end{array}$ \\
\hline \multicolumn{4}{|c|}{ Referred patients to cancer genetics } \\
\hline Always & $\begin{array}{c}60.7 \% \\
(88)\end{array}$ & $\begin{array}{c}33.3 \% \\
(7)\end{array}$ & $\begin{array}{c}100 \% \\
(4)\end{array}$ \\
\hline Often/Sometimes & $\begin{array}{c}33.8 \% \\
(49)\end{array}$ & $\begin{array}{c}61.9 \% \\
(13)\end{array}$ & $\begin{array}{l}0 \% \\
(0)\end{array}$ \\
\hline Never/Unsure & $\begin{array}{c}5.5 \% \\
(8)\end{array}$ & $\begin{array}{c}4.8 \% \\
(1) \\
\end{array}$ & $\begin{array}{l}0 \% \\
(0) \\
\end{array}$ \\
\hline
\end{tabular}


Regarding the timing of testing, $64.5 \%$ of respondents indicated that they ordered testing at diagnosis (Figure 1). 37.3\% of providers ordered before starting chemotherapy, and 34.3\% ordered after beginning chemotherapy. Other responses included when a patient relapsed, after completion of chemotherapy, or after surgery has been performed.

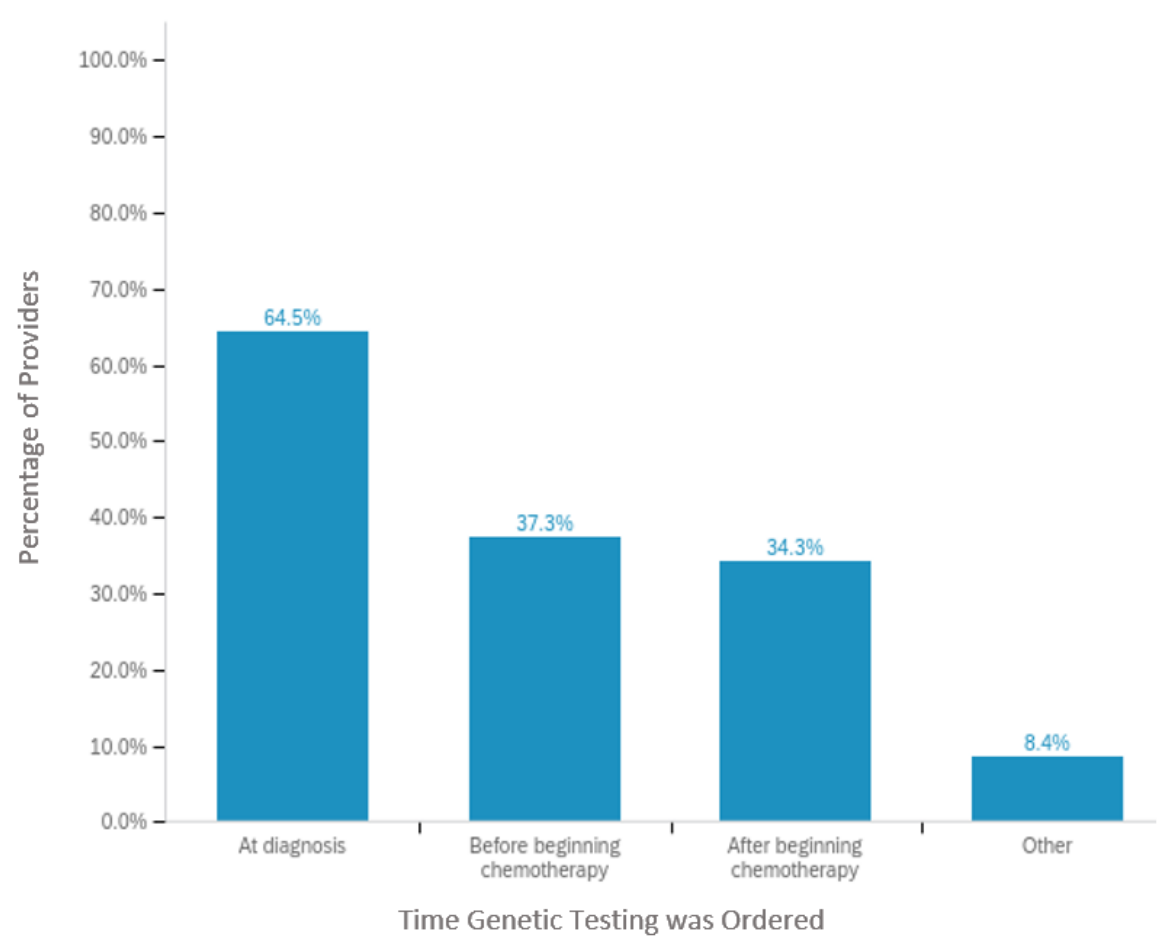

Figure 1. Percentage of providers who ordered genetic testing at indicated times in patient treatment

Respondents were also asked to indicate the types of testing that they had ordered for patients with EOC in the past year and were permitted to select multiple types of testing. Panel testing was performed by $95.8 \%$ of providers (Figure 2). The second most frequently selected type of testing $(44.0 \%)$ was somatic testing with reported germline mutations, followed by somatic testing without reported germline mutations (30.1\%). Only $13.9 \%$ of providers indicated that they performed $B R C A 1 / 2$ analysis alone in the past year. Other responses specified that test selection is deferred to genetic counselors. 


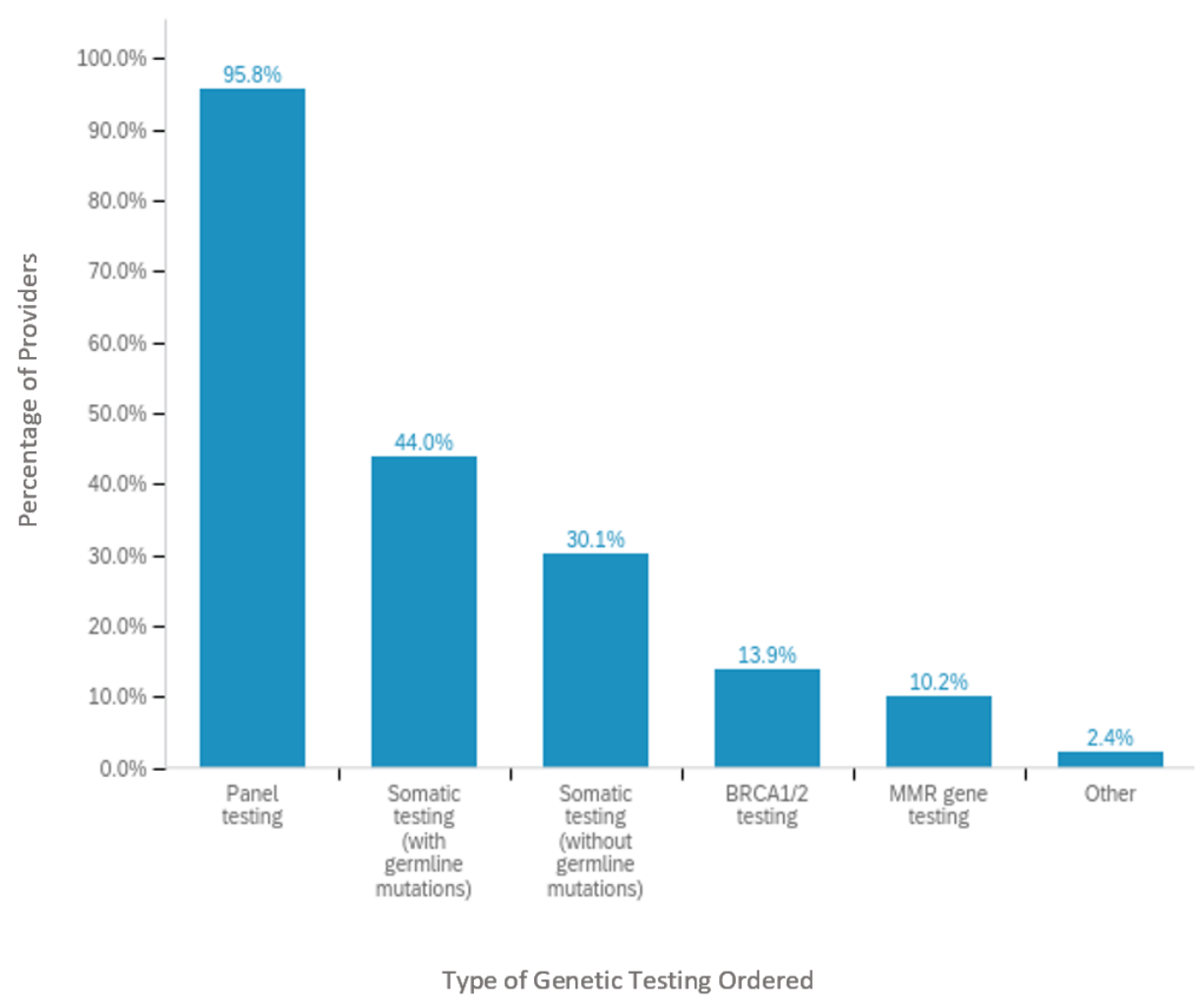

Figure 2. Percentage of providers who ordered indicated type of genetic testing

The majority of respondents (53.6\%) felt that none of the potential barriers listed prevented or hindered them from ordering genetic testing. The most commonly cited barriers to testing were patient disinterest (30.4\%) and insurance coverage concerns (13.7\%). Other responses $(9.5 \%)$ specified long wait times for genetic counseling appointments, the financial confusion that testing causes patients, and a lack of patient interest to share information with family. Three of the four providers who never ordered genetic testing clarified that genetic counselors are consulted to order testing based on the patient's personal history and their family history. No providers felt that genetic testing was unnecessary or were confused by genetic testing.

Providers were asked to select the timing at which they referred patients with EOC to cancer genetics services in the past year. About half of providers referred patients before genetic testing for pre-test counseling or at diagnosis (Figure 3). Almost 25\% of providers referred patients 
after ordering testing if there was a positive result; $14.3 \%$ referred patients after ordering testing if the result was unclear. $3.1 \%$ of providers refer after testing if there is a negative result. Other responses included after somatic testing if a germline mutation is suspected, when a result is in a gene the provider is not familiar with, when family history warrants further evaluation, or upon patient request.

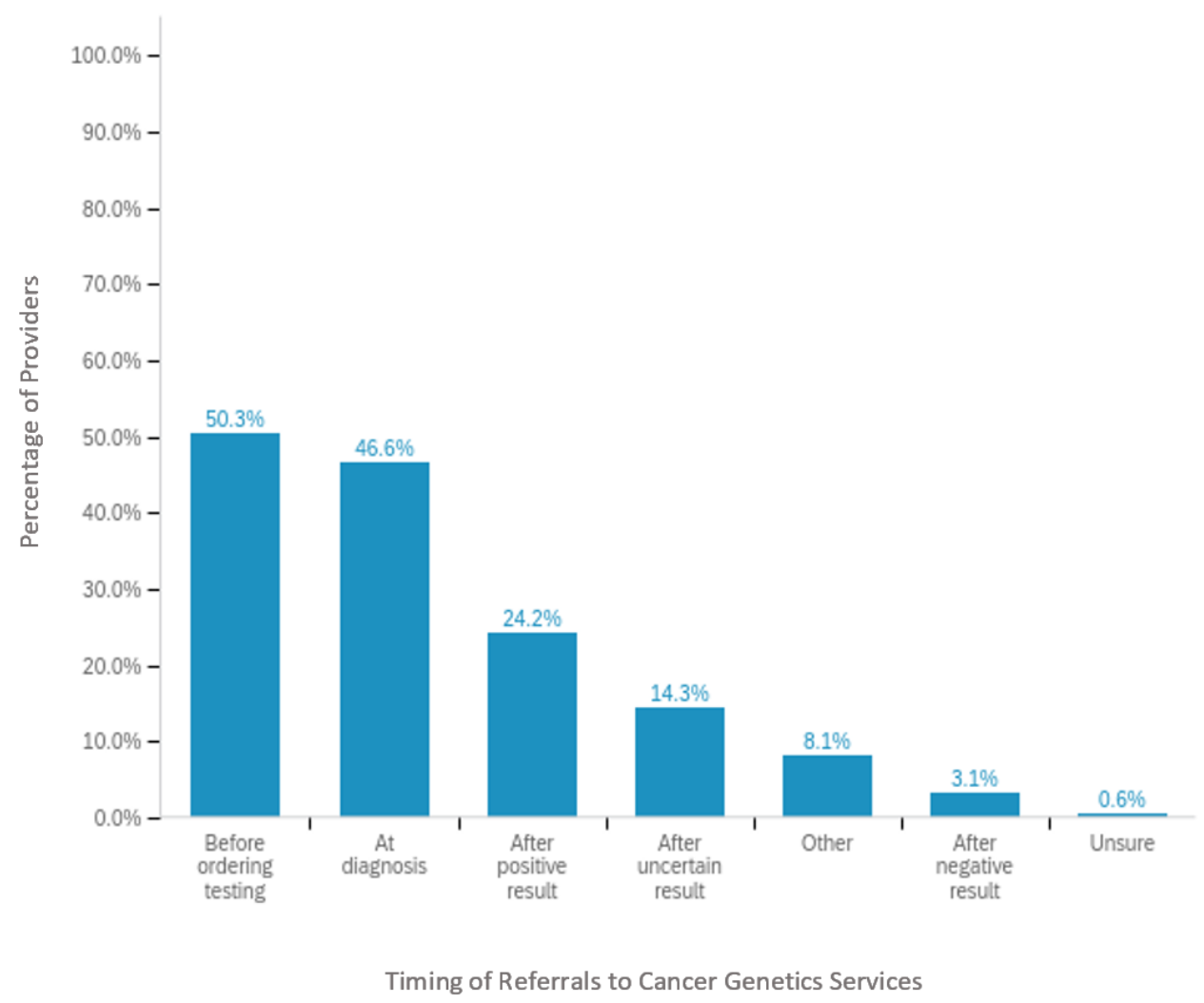

Figure 3. Percentage of providers who referred patients to cancer genetics services at indicated times in patient treatment

$40 \%$ of providers did not feel that any of the listed barriers prevented or hindered them from referring a patient to cancer genetics services. A third of providers felt that patient disinterest was a barrier. $17.3 \%$ of providers felt that they provided the necessary services to the patient. Insurance coverage and burdening patients with additional appointments were less commonly 
indicated as barriers. Lack of cancer genetics services in the area was selected by $5 \%$ of providers. No respondents cited confusion about cancer genetics services as a barrier to referrals.

\subsubsection{Genetics Education}

Providers were asked to indicate if they had attended educational courses, events, and programs. The most commonly reported form of genetics education (71.2\%) was talks at conferences focused on genetics. Continuing education events, genetics courses in medical school, and webinars were the next most commonly selected responses. About $10 \%$ of respondents did not have experience with any of the genetics education forms listed. Other forms of genetics education specified included a Masters or PhD in Genetics, research, on-the-job training in genetics, years of experience, and the City of Hope course.

\subsubsection{Provider Confidence}

Five questions were posed to assess providers' confidence level with various aspects of cancer genetics services: taking a detailed family history, ordering genetic testing, interpreting results, counseling a patient on the meaning of results, and making a referral to cancer genetics services. Provider confidence levels were broken down and analyzed by testing practices. The majority of those who always ordered genetic testing were very confident in each part of the testing process; however, only $43.4 \%$ of these providers were very confident in their ability to take a detailed family history, and $13.1 \%$ described themselves as not confident. Similarly, almost 50\% of those who often or sometimes ordered testing were only somewhat confident with this process. The majority of these providers were somewhat or not confident with aspects of the testing process, 
except when it comes to knowing which patients to refer. $86 \%$ of providers who sometimes or often order testing are very confident in their ability to identify patients that warrant a referral. Only four providers never ordered testing, and their confidence levels varied. Three of the four providers were not confident with their ability to order testing, and all four were very confident in their ability to appropriately make referrals.

Fisher's exact test determined there was no statistically significant difference between providers with different testing practices in regard to their confidence taking a detailed family history and deciding which patients to refer to cancer genetics. However, there was a significant difference between providers in confidence ordering testing as well as interpreting and counseling a patient on the meaning of genetic test results. Providers who always ordered genetic testing tended to describe themselves as very confident, while many providers who often or sometimes ordered testing tended to be somewhat confident (Table 5). 
Table 5. Provider Confidence with Aspects of Cancer Genetics Services by Testing Practices

\begin{tabular}{|c|c|c|c|c|}
\hline $\begin{array}{c}\text { Confidence } \\
\text { Level }\end{array}$ & $\begin{array}{l}\text { I always ordered } \\
\text { genetic testing }\end{array}$ & $\begin{array}{c}\text { I often/sometimes } \\
\text { ordered genetic testing }\end{array}$ & $\begin{array}{l}\text { I never ordered } \\
\text { genetic testing }\end{array}$ & $\mathbf{p}$ \\
\hline \multicolumn{5}{|c|}{ Taking a detailed, 3-generation family history } \\
\hline Very confident & $\begin{array}{c}43.8 \% \\
(63) \\
\end{array}$ & $\begin{array}{c}38.1 \% \\
(8)\end{array}$ & $\begin{array}{l}50.0 \% \\
(2)\end{array}$ & \multirow{3}{*}{0.968} \\
\hline $\begin{array}{r}\text { Somewhat } \\
\text { confident }\end{array}$ & $\begin{array}{c}43.0 \% \\
(62) \\
\end{array}$ & $\begin{array}{c}47.6 \% \\
(10) \\
\end{array}$ & $\begin{array}{l}50.0 \% \\
(2) \\
\end{array}$ & \\
\hline Not confident & $\begin{array}{c}13.2 \% \\
(19)\end{array}$ & $\begin{array}{l}14.3 \% \\
(3)\end{array}$ & $\begin{array}{c}0.0 \% \\
(0)\end{array}$ & \\
\hline \multicolumn{5}{|c|}{ Ordering genetic testing } \\
\hline Very confident & $\begin{array}{c}61.0 \% \\
(86) \\
\end{array}$ & $\begin{array}{l}45.0 \% \\
(9) \\
\end{array}$ & $\begin{array}{l}25.0 \% \\
(1) \\
\end{array}$ & \multirow{3}{*}{$0.008 *$} \\
\hline $\begin{array}{r}\text { Somewhat } \\
\text { confident }\end{array}$ & $\begin{array}{c}30.5 \% \\
(43)\end{array}$ & $\begin{array}{l}45.0 \% \\
(9)\end{array}$ & $\begin{array}{c}0.0 \% \\
(0)\end{array}$ & \\
\hline Not confident & $\begin{array}{c}8.5 \% \\
(12) \\
\end{array}$ & $\begin{array}{c}10.0 \% \\
(2) \\
\end{array}$ & $\begin{array}{c}75.0 \% \\
(3) \\
\end{array}$ & \\
\hline \multicolumn{5}{|c|}{ Interpreting all possible results } \\
\hline Very confident & $\begin{array}{c}60.0 \% \\
(87)\end{array}$ & $\begin{array}{l}28.6 \% \\
(6)\end{array}$ & $\begin{array}{l}50.0 \% \\
(2)\end{array}$ & \multirow{3}{*}{$0.005^{*}$} \\
\hline $\begin{array}{r}\text { Somewhat } \\
\text { confident }\end{array}$ & $\begin{array}{c}37.2 \% \\
(54)\end{array}$ & $\begin{array}{c}57.1 \% \\
(12) \\
\end{array}$ & $\begin{array}{l}25.0 \% \\
(1)\end{array}$ & \\
\hline Not confident & $\begin{array}{c}2.8 \% \\
(4)\end{array}$ & $\begin{array}{c}14.3 \% \\
(3)\end{array}$ & $\begin{array}{l}25.0 \% \\
(1)\end{array}$ & \\
\hline \multicolumn{5}{|c|}{ Counseling a patient on meaning } \\
\hline Very confident & $\begin{array}{c}62.8 \% \\
(91) \\
\end{array}$ & $\begin{array}{c}19.0 \% \\
(4)\end{array}$ & $\begin{array}{l}50.0 \% \\
(2)\end{array}$ & \multirow{3}{*}{$0.002 *$} \\
\hline $\begin{array}{r}\text { Somewhat } \\
\text { confident }\end{array}$ & $\begin{array}{c}35.2 \% \\
(51)\end{array}$ & $\begin{array}{c}76.2 \% \\
(16) \\
\end{array}$ & $\begin{array}{c}50.0 \% \\
(2)\end{array}$ & \\
\hline Not confident & $\begin{array}{c}2.1 \% \\
(3) \\
\end{array}$ & $\begin{array}{c}4.8 \% \\
(1)\end{array}$ & $\begin{array}{c}0.0 \% \\
(0)\end{array}$ & \\
\hline \multicolumn{5}{|c|}{ Deciding which patients to refer to cancer genetics } \\
\hline Very confident & $\begin{array}{c}84.8 \% \\
(123) \\
\end{array}$ & $\begin{array}{c}85.7 \% \\
(18) \\
\end{array}$ & $\begin{array}{c}100 \% \\
(4)\end{array}$ & \multirow{3}{*}{0.999} \\
\hline $\begin{array}{r}\text { Somewhat } \\
\text { confident }\end{array}$ & $\begin{array}{c}15.2 \% \\
(22) \\
\end{array}$ & $\begin{array}{c}14.3 \% \\
(3) \\
\end{array}$ & $\begin{array}{c}0.0 \% \\
(0) \\
\end{array}$ & \\
\hline Not confident & $\begin{array}{c}0.0 \% \\
(0)\end{array}$ & $\begin{array}{c}0.0 \% \\
(0)\end{array}$ & $\begin{array}{c}0.0 \% \\
(0)\end{array}$ & \\
\hline
\end{tabular}




\subsection{Discussion}

\subsubsection{Current Genetic Testing and Referral Practices by Oncology Providers}

Current NCCN guidelines recommend that all patients with epithelial ovarian cancer (EOC) be offered germline genetic testing. ${ }^{4,7}$ The first goal of this study was to gain an understanding of how oncology providers are currently ordering and utilizing genetic testing results in their practice for patients with EOC. Results from this study are encouraging, demonstrating that the overwhelming majority (85\%) of oncology providers always order genetic testing for patients with EOC. Providers most often order genetic testing at diagnosis and typically order multi-gene panel or somatic testing. Many providers did not feel that listed barriers to testing and referrals applied to them, although patient disinterest and insurance coverage issues were sometimes indicated.

Recent literature has found that only about $35 \%$ of patients with ovarian cancer have received genetic testing in spite of guidelines recommending testing for all of these patients. ${ }^{17}$ However, this study found that $85 \%$ of gynecologic oncologists always ordered testing for patients with EOC in the past year. With such a high rate of providers always ordering testing, one would expect a higher percentage of patients to have received testing. There are several possible explanations for this discrepancy. First, this study focused on provider testing practice within the past year across the country. The study that estimated $35 \%$ of ovarian cancer patients to have received genetic testing collected data for women in California and Georgia only from 2012-2019. Additionally, the recent emergence of companion testing may also be increasing the proportion of patients with ovarian cancer who have received testing; Myriad Genetics launched their version of companion testing in 2014, for example. Therefore, better awareness of guidelines and improved 
options for testing may have increased testing rates in very recent years. Additionally, providers might be ordering genetic testing for their patients with EOC, but genetic testing may not always be completed. Disease-related burden or patient disinterest could be preventing patients from going through with the testing, despite the order being in place. About $30 \%$ of providers listed patient disinterest as a barrier to testing, so it is possible that this is contributing to the discrepancy in ordering versus testing rates.

The high prevalence of multi-gene testing found in this study is in concordance with other recent studies. ${ }^{17,95}$ The utility of multi-gene panel testing is well-established, as it can detect more pathogenic variants in clinically actionable genes than $B R C A 1 / 2$ testing alone ${ }^{81,95}$ Interestingly, a third of providers ordered somatic testing without reported germline mutations despite the high prevalence of germline pathogenic variants in patients with EOC. ${ }^{2,67}$ It is possible that patients were not interested in germline testing. Providers may perform follow-up germline testing if there is a somatic result that is suspicious for being germline or refer individuals with suspicious tumor test results to cancer genetics professionals. Additionally, current ASCO guidelines recommend that women with EOC with negative germline testing should have somatic testing. ${ }^{5}$ It is therefore also possible that providers ordered somatic testing as a follow-up test to negative germline testing. Because this survey only asked providers to list all types of testing they have ordered within the last year, further research is needed to clarify the context in which somatic testing is being ordered.

In this study, testing at diagnosis was the most commonly reported timing of testing, in compliance with current guidelines. ASCO guidelines recommend germline genetic testing at the diagnosis of EOC in order to determine whether therapy with PARP inhibitors is indicated and to make decisions regarding neoadjuvant chemotherapy. ${ }^{5}$ Interestingly, the majority of providersregardless of their testing practice—indicated that they often or sometimes use test results to guide 
treatment. However, both positive and negative genetic test results are informative for treatment and prognosis. Negative genetic test results can predict response to therapies and rule out the use of certain tailored therapies. ${ }^{7,8,78}$ Perhaps providers do not consider negative genetic test results to be informative for treatment purposes as no tailored therapies are available to wild-type patients. Further research is needed to investigate the situations in which providers do not use genetic test results to guide treatment. Testing was also ordered before or after beginning chemotherapy by about a third of survey respondents. The survey did not probe further into why testing was ordered at the indicated times, but there are many possible explanations. The patient may not have been seen by the provider until this stage in their treatment, or there could have been delays in being able to proceed with testing. A frequently mentioned "other" response to testing barriers was long wait times for genetic counseling appointments. Only four respondents indicated that genetic counselors handle all genetic testing for patients EOC. This further supports the notion that an alternative service pathway for patients with EOC to undergo genetic testing is needed to improve access, as many other studies have found that there are not enough cancer genetics providers to meet patient needs. ${ }^{15,105,106}$

The majority of providers that always ordered genetic testing for patients with EOC also always referred these patients to cancer genetics services, while those who ordered testing less often tended to refer patients less frequently. One possible interpretation of this trend is that providers who order their own testing have a greater knowledge of genetics and are more likely to recognize their limitations in providing all necessary services surrounding genetic testing, such as coordinating testing for family members and addressing patient emotions. This would be in line with other studies which have found that providers who have a greater familiarly and knowledge in genetics have higher rates of referrals. ${ }^{117,122,126}$ This study did not examine the reasons why these 
providers were making referrals to genetics services. Apart from patient request or eligibility, commonly described motivations for referrals in current literature are to enhance risk assessment, improve medical management, and address concern for family members. ${ }^{125}$ Additionally, recent studies have found that many non-genetics healthcare professionals experience difficulty managing patient emotions and providing support. ${ }^{12,126}$ When asked about barriers to referrals, only $20 \%$ of providers surveyed responded that they provided all the needed services to the patients. Therefore, one explanation for the high rate of referrals among providers who order their own testing is that they recognize the benefits of genetic counseling and the additional services that can be provided by genetics professionals.

\subsubsection{Types of Genetics Education}

The most common forms of genetics education that respondents reported to have received were talks at conferences about genetics, Continuing Education events, and webinars. These platforms, while not formal training in genetics, have been frequently utilized by providers in the

past and have been shown to increase genetics knowledge in previous studies. ${ }^{123,124}$ Some providers specified that multiple years of experience in their career supplied their genetics training. Providers with multiple years of experience should still be encouraged to improve their knowledge in genetics due to the rapidly evolving nature of the field. ${ }^{117}$ Educational sessions should continue to be offered in a variety of platforms to ensure accessibility. ${ }^{114,120}$ 


\subsubsection{Confidence Levels of Oncology Providers with Genetic Testing Process}

Overall, providers were most confident in deciding which patients to refer to cancer genetics services and were least confident in taking a detailed, 3-generation family history. Confidence levels with these aspects of genetics did not significantly differ between providers with different testing practices. Previous studies have suggested that non-genetics healthcare providers are proficient at identifying high-risk patient that require referrals, but they tend to be less adept at identifying moderate or low risk patients. ${ }^{118,126}$ While high confidence levels for referring patients is reassuring, this study did not assess provider knowledge with or appropriateness of referrals being made. It is important that future studies ensure that appropriate referrals are being made for all patients. Confidence levels for obtaining a family history were slightly lower than expected; less than half of respondents felt very confident performing this task. One recent study found that 91\% of non-genetics healthcare providers felt confident taking a cancer genetics family history, and a survey of breast surgeons found that $90 \%$ of respondents were willing and able to take 3 generation pedigrees for patients. ${ }^{112,114}$ Further research can determine what providers are struggling with when taking a family history.

Finally, provider confidence with ordering testing, interpreting all possible results, and counseling the patients on the meaning of the results significantly differed between providers with different testing practices. Providers who always ordered their own genetic tests tended to label themselves as "very confident" in these tasks, while providers who ordered their own tests only often or sometimes labeled themselves "somewhat confident." Many studies have demonstrated that the more confident a provider is with aspects of genetics services, the more likely they are to deliver those services themselves. ${ }^{112-114,125,126}$ These results are therefore not surprising and are in agreement with current literature. Recent studies have also shown that many providers struggle 
with appropriately interpreting a variant of uncertain significance, negative results in the context of a strong family history, and results in less well-studied genes. ${ }^{18,19,62,112,127}$ These issues may be playing a role in provider confidence, but ultimately future studies are required to tease out why providers who order their own genetic testing less frequently tend to be less confident with interpreting results and counseling patients.

\subsubsection{Study Limitations and Future Directions}

This study provided new information on oncology providers' genetic testing practices for patients with EOC, but several limitations exist. The sample may not be truly representative of all oncology providers, as there was a low response rate. The results may also be subject to response bias, as providers who are more interested or more confident in cancer genetics may have been more inclined to respond to the survey. Finally, this survey was descriptive in nature, and so underlying causes were not able to be examined.

In spite of the limitations, the results of this study are encouraging and suggest that mainstreaming genetic testing for patients with EOC by oncology providers is an achievable service delivery model. Future studies should continue to delve into this pathway by examining providers' genetics knowledge and the appropriateness of testing and referrals. More specific questions, perhaps with case scenarios or general knowledge questions, could help to elicit whether providers are accurately ordering, interpreting, and acting on genetic information. It would also be of interest to learn more about why the trends observed in this study exist. For example, with such a high percentage of providers always ordering testing, one would expect a higher percentage of patients to have received testing. Future studies can help to determine if testing rates have dramatically increased in recent years or if there is a significant absence of follow-though with 
genetic test orders. Additionally, it would be of interest to determine the context that somatic testing is being ordered. Are providers ordering it alone, or prior to or after germline testing? Is a particular method more cost effective? Examining answers to questions such as these can help to improve this oncologist-led alternative service delivery pathway and increase access to genetics services.

\subsection{Conclusion}

As up to $25 \%$ of epithelial ovarian cancer diagnoses have an underlying genetic predisposition, accessible genetic testing is crucial to appropriately guide treatment for these patients. This study adds to the growing body of evidence that oncologist-led genetic testing for patients with EOC is a potentially feasible alternative service delivery model. The majority of oncology providers are ordering multi-gene testing for this patient population and most commonly are doing so at diagnosis, in concordance with current NCCN and ASCO guidelines. Additionally, most providers who order testing independently are still referring patients to cancer genetics services, which can help to address patient emotions and risk to family members in more detail when necessary. Genetics educational support has been consistently shown to be highly desired, and results of this study suggest that genetics talks at conferences and continuing education events are popular modalities. Overall, oncologist-led genetic testing for patients with EOC with appropriate referrals to genetics services appears to be an achievable way to increase access to genetics services, but further research is necessary to tease out differences in provider confidence and investigate reasons for trends observed in this study. 


\subsection{Relevance to Genetic Counseling and Public Health}

The implications of this study's results extend into both genetic counseling and public health. Assessing and monitoring community needs is the first essential service of public health. It is well-established that patients with epithelial ovarian cancer require genetics services for comprehensive care. The Center for Disease Control considers both Hereditary Breast and Ovarian Cancer syndrome and Lynch syndrome to be Tier 1 genomic conditions; there is significant evidence that identifying individuals with these conditions can have a significant public health impact. ${ }^{135}$ The shortage of genetics healthcare professionals necessitates alternative service delivery models in order to increase access to genetics services. Some service models can still incorporate genetics professionals themselves, such as telephone, telemedicine, pre-recorded videos, or group genetic counseling. ${ }^{107}$ However, these models alone still cannot meet the current demand. If every patient diagnosed with EOC should be offered genetic testing, then genetic testing cannot be solely completed by genetics professionals.

This study sought to investigate a potential solution to the low percentage of genetic testing among patients with EOC, which reflects the second essential service of public health. The low rate of genetic testing is a hazard affecting these patients, as tailored treatment opportunities could be missed and at-risk family members may not be appropriately identified. ${ }^{17}$ The results of this study suggest that oncologist-led genetic testing for patients with EOC is a feasible alternative service delivery model, with $85 \%$ of gynecologic oncology providers always ordering testing for these patients. Supporting this service pathway has the potential to improve testing accessibility and increased testing rates, which in turn could lead to improved health outcomes for patients and their families. 
Within public health, there are three core functions: assessment, policy development, and assurance. This study assessed how oncology providers are using genetic testing in their practice and how confident they feel about different aspects of cancer genetics. This data is critical information that can be used to identify aspects of this service model that are working well and aspects that require targeted outreach to improve the process. This survey demonstrated that providers are generally ordering multi-gene panel testing at diagnosis for these patients, which is in compliance with current guidelines. Additionally, providers were very confident in their ability to know which patients require a referral to cancer genetics services. Providers were generally less confident in taking a detailed family history, so educational outreaches can strive to highlight the importance of family history and the familial implications of genetic test results. Addressing the aspects of genetics services that providers struggle with helps to assure that oncologist-led genetic testing delivers appropriate care.

This study provides valuable information about the current genetic testing practice of gynecologic oncology providers. Future studies can continue to explore this practice by investigating provider knowledge and the appropriateness of referrals. Cancer genetic professionals have a key role to play in supporting this service pathway. They can help to educate and assist providers with questions that arise during the testing process. Furthermore, as referrals for positive or unclear results are a pivotal aspect of this service model, cancer genetics professionals are essential for comprehensive care of patients and their family members. The public health impact that this service model could provide is significant and warrants additional investigation. 


\section{Appendix A IRB Approval}

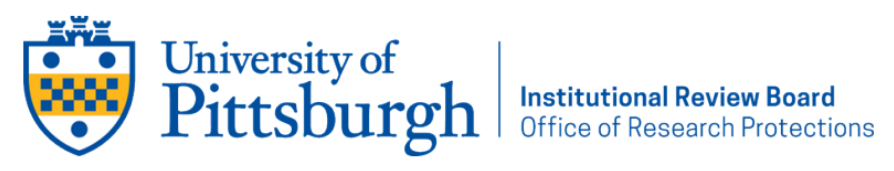

\section{EXEMPT DETERMINATION}

\begin{tabular}{|l|l|}
\hline Date: & August 14, 2020 \\
\hline IRB: & STUDY20070321 \\
\hline PI: & Megan Czekalski \\
\hline Title: & $\begin{array}{l}\text { Mainstreaming Genetic Testing for Epithelial Ovarian Cancer by Oncology Providers: A } \\
\text { Survey of Current Practice }\end{array}$ \\
\hline Funding: & None \\
\hline
\end{tabular}

The Institutional Review Board reviewed and determined the above referenced study meets the regulatory requirements for exempt research under 45 CFR 46.104.

Determination Documentation

\begin{tabular}{|l|l|}
\hline Determination Date: & 8/14/2020 \\
\hline Exempt Category: & (2)(ii) Tests, surveys, interviews, or observation (low risk) \\
\hline Approved & $\begin{array}{l}\bullet \text { Czekalski Survey, Category: Data Collection; } \\
\text { Documents: }\end{array}$ \\
& $\begin{array}{l}\text { - Czekalski HRP-721, Category: IRB Protocol; } \\
\end{array}$ \\
\hline
\end{tabular}

If you have any questions, please contact the University of Pittsburgh IRB Coordinator, Larry Ivanco.

Please take a moment to complete our Satisfaction Survey as we appreciate your feedback. 


\section{Appendix B Survey Content}

This study is being conducted by Megan Czekalski, a genetic counseling student at the University of Pittsburgh, for the completion of her thesis project. The purpose of this research study is to investigate current practices by oncology providers regarding cancer genetic testing for patients with epithelial ovarian cancer. We are surveying all members of the Society of Gynecologic Oncologists with this brief questionnaire, which will take approximately 15 minutes to complete. The survey collects information on your background (e.g. specialty, years of experience, etc.) and how you incorporate genetic testing in your practice. There are no foreseeable risks associated with this project, nor are there any direct benefits to you. You will not receive any payment for participation. Your responses will not be identifiable in any way, and all responses are confidential. Your participation is voluntary, and you may discontinue answering the survey questions at any time. Should you have any questions, you can contact Megan Czekalski at mac547@ pitt.edu.

Q1 Are you in clinical practice currently or have you been in clinical practice within the past year?

Yes

No

Decline to answer

Q2 Over the past year, approximately what percentage of your total practice involved patients diagnosed with epithelial ovarian cancer?

I did not see any patients diagnosed with epithelial ovarian cancer in the past year

$1-25 \%$

$26-50 \%$

$51-75 \%$

$76-100 \%$

Unsure 
Many of the following questions will ask about genetic testing in your practice. For the purposes of this survey, we are interested in germline (hereditary) genetic testing only. Unless otherwise specified, only include somatic (tumor) genetic testing if germline results are also reported.

Q3 How often have you ordered genetic testing for patients with epithelial ovarian cancer in the past year?

Never

Sometimes

Often

Always

Unsure

Q4 When did you typically order genetic testing for patients with epithelial ovarian cancer in the past year? Select all that apply.

At diagnosis

Before beginning chemotherapy

After beginning chemotherapy

Other (please specify):

Unsure 
Q5 What kind of genetic testing did you typically order for patients with epithelial ovarian cancer in the past year? Select all that apply.

\section{BRCA1/2 testing}

Mismatch repair gene testing (e.g. MLH1, PMS2, MSH2, MSH6; typically associated with Lynch syndrome)

Panel testing (e.g. multi-gene testing that examines BRCA1/2 and other genes at the same time)

Somatic testing (with reported germline mutations)

Somatic testing (without reported germline mutations)

$\square$ Other (please specify):

Unsure 
Q6 What barriers hinder or prevent you from ordering genetic testing for patients with epithelial ovarian cancer? Select all that apply.

I do not think genetic testing is necessary

It will not change medical management for the patient

I am concerned about insurance discrimination against patients

I am concerned about insurance not covering genetic testing

My patient was not interested

I am confused by genetic testing

Other (please specify):

None of these apply

Q7 How often have you used genetic testing results to guide the treatment (e.g. chemotherapy) of patients with epithelial ovarian cancer in the past year?

Never

Sometimes

Often

Always

Unsure 
Q8 How often have you referred patients with epithelial ovarian cancer to cancer genetics services in the past year?

Never

Sometimes

Often

Always

Unsure

Q9 When did you typically refer patients with epithelial ovarian cancer to cancer genetics services in the past year? Select all that apply.

At diagnosis

Before genetic testing for pre-test counseling

After ordering genetic testing if there is a positive result

After ordering genetic testing if there is an uncertain result

After ordering genetic testing if there is a negative result

Other (please specify):

Unsure 
Q10 What barriers hinder or prevent you from referring patients with epithelial ovarian cancer to cancer genetics services? Select all that apply.

I provide the needed services to patients

I am concerned about insurance discrimination against patients

I am concerned about insurance not covering genetic counseling or testing

I do not want to burden my patients with additional appointments

My patient was not interested

There are no cancer genetics services in the area

I do not know who to refer my patients to

I am confused about these services

Other (please specify):

None of these apply 
Q11 Have you completed any training or continuing education in genetics? Select all that apply.

Completed course(s) in genetics in medical school

Completed a residency or fellowship in genetics

Watched webinar(s)

Attended talk(s) at conference(s) about genetics

Attended Continuing Education event(s)

Taken formal course(s) in genetics after medical school

Obtained certification(s) in genetics

Other (please specify):

None of these apply

Q12 How confident are you in taking a detailed, 3-generation family history?

Not confident

Somewhat confident

Very confident

Decline to answer 
Q13 How confident are you in ordering genetic testing?

Not confident

Somewhat confident

Very confident

Decline to answer

Q14 How confident are you in interpreting all possible genetic testing results (e.g. positive, negative, or a VUS)?

Not confident

Somewhat confident

Very confident

Decline to answer

Q15 How confident are you in counseling a patient on the meaning of their genetic testing results?

Not confident

Somewhat confident

Very confident

Decline to answer 
Q16 How confident are you in deciding which patients should be referred to cancer genetics?

Not confident

Somewhat confident

Very confident

Decline to answer

Q17 What is your current job title?

Gynecologic oncologist

Medical oncologist

Surgical oncologist

Nurse practitioner

Physician assistant

Registered nurse

Other (please specify):

Decline to answer 
Q18 What is your primary area of medical practice?

Gynecology/obstetrics

Internal medicine

Family practice

Other (please specify):

Decline to answer

Q19 Which of the following best describes the location where you work? Select all that apply.

Rural

Suburban

Urban

Other (please specify):

Decline to answer 
Q20 Which of the following best describes your practice setting? Select all that apply.

Private practice

Group practice

Hospital based

Academic center

Other (please specify):

Decline to answer

Q21 Approximately how many years of experience do you have in patient care?

0-9

10-19

$20-29$

30 or more

Decline to answer 
Q22 Which category below includes your age?

29 or younger

$30-49$

$50-69$

70 years or older

Decline to answer

Q23 What gender do you identify as?

Female

Male

Nonbinary

Other (please specify):

Decline to answer 
Q24 What ethnicity do you identify as? Select all that may apply.

American Indian or Alaskan Native

Asian

Black or African-American

Native Hawaiian or other Pacific islander

White

Other (please specify):

Decline to answer

Q25 Are you of Hispanic, LatinX, or Spanish origin?

Yes

No

Decline to answer 


\section{Appendix C Recruitment E-mail}

\section{Dear SGO member,}

I'm reaching out to you today to invite you to participate in a research study. This study is being conducted by Megan Czekalski, a second-year genetic counseling student at the University of Pittsburgh.

She is conducting an online, anonymous survey as part of her master's thesis project entitled "Mainstreaming Genetic Testing for Epithelial Ovarian Cancer by Oncology Providers: A Survey of Current Practice." This research project seeks to investigate current practices by oncology providers regarding cancer genetic testing for patients with epithelial ovarian cancer. We are surveying all members of the Society of Gynecologic Oncologists with this brief questionnaire, which will take approximately 15 minutes to complete.

The survey collects information on your background (e.g., specialty, years of experience, etc.) and how you incorporate genetic testing in your practice. There are no foreseeable risks associated with this project, nor are there any direct benefits to you. You will not receive any payment for participation. Your responses will not be identifiable in any way, and all responses are confidential. Your participation is voluntary, and you may discontinue answering the survey questions at any time.

\section{To participate in the survey, please use this link:}

https://pitt.co1.qualtrics.com/jfe/form/SV_8cEm74MY0W2mMJv

Disclaimer: This survey is not in connection to the Society of Gynecologic Oncology.

This project is being conducted in partial fulfillment of a Master of Science in Genetic Counseling at the University of Pittsburgh. This study has been approved by the University of Pittsburgh Institutional Review Board, STUDY20070321.

Thank you for your time and participation. Should you have any comments or questions, please feel free to contact Megan at mac547@ pitt.edu. You may also reach out to other members of the thesis committee:

Rachelle C. Huziak, MS, CGC: huziakr@upmc.edu

Phuong Mai, MD, MS: maip@upmc.edu

Andrea L. Durst, MS, DrPH, CGC: adurst@ pitt.edu 


\section{Appendix D Statistical Analysis}

\section{CONFIDENCE TAKING FAMILY HISTORY}

. tab fhx order_group, exact exp

\begin{tabular}{|c|}
\hline Key \\
\hline $\begin{array}{c}\text { frequency } \\
\text { expected frequency }\end{array}$ \\
\hline
\end{tabular}

Enumerating sample-space combinations:

stage 3: enumerations $=1$

stage 2: enumerations $=1$

stage 1: enumerations $=0$

\begin{tabular}{|c|c|c|c|c|}
\hline \multirow[b]{2}{*}{ fhx } & \multicolumn{3}{|c|}{ order_group } & \multirow[b]{2}{*}{ Total } \\
\hline & Always & Never & OS & \\
\hline \multirow[t]{2}{*}{ Not confident } & 19 & 0 & 3 & 22 \\
\hline & 18.7 & 0.5 & 2.7 & 22.0 \\
\hline \multirow[t]{2}{*}{ Somewhat confident } & 62 & 2 & 10 & 74 \\
\hline & 63.1 & 1.8 & 9.2 & 74.0 \\
\hline \multirow[t]{2}{*}{ Very confident } & 63 & 2 & 8 & 73 \\
\hline & 62.2 & 1.7 & 9.1 & 73.0 \\
\hline \multirow[t]{2}{*}{ Total } & 144 & 4 & 21 & 169 \\
\hline & 144.0 & 4.0 & 21.0 & 169.0 \\
\hline
\end{tabular}

Fisher's exact $=$

0.968

\section{CONFIDENCE ORDERING GENETIC TESTING}

. tab order_test order_group, exact exp

$$
\begin{array}{|c|}
\hline \text { Key } \\
\hline \text { frequency } \\
\text { expected frequency }
\end{array}
$$

Enumerating sample-space combinations:

stage 3: enumerations $=1$

\begin{tabular}{|c|c|c|c|c|}
\hline \multirow[b]{2}{*}{ order_test } & \multicolumn{3}{|c|}{ order_group } & \multirow[b]{2}{*}{ Total } \\
\hline & Always & Never & OS & \\
\hline \multirow{2}{*}{ Not confident } & 12 & 3 & 2 & 17 \\
\hline & 14.5 & 0.4 & 2.1 & 17.0 \\
\hline \multirow[t]{2}{*}{ Somewhat confident } & 43 & 0 & 9 & 52 \\
\hline & 44.4 & 1.3 & 6.3 & 52.0 \\
\hline \multirow[t]{2}{*}{ Very confident } & 86 & 1 & 9 & 96 \\
\hline & 82.0 & 2.3 & 11.6 & 96.0 \\
\hline \multirow[t]{2}{*}{ Total } & 141 & 4 & 20 & 165 \\
\hline & 141.0 & 4.0 & 20.0 & 165.0 \\
\hline
\end{tabular}

stage 2: enumerations $=14$

stage 1: enumerations $=0$

Fisher's exact $=$

0.008 


\section{CONFIDENCE INTERPRETING TESTING}

. tab interpret_test order_group, exact exp

$$
\begin{array}{|c|}
\hline \text { Key } \\
\hline \text { frequency } \\
\text { expected frequency }
\end{array}
$$

Enumerating sample-space combinations:

stage 3: enumerations $=1$

stage 2: enumerations $=12$

stage 1: enumerations $=0$

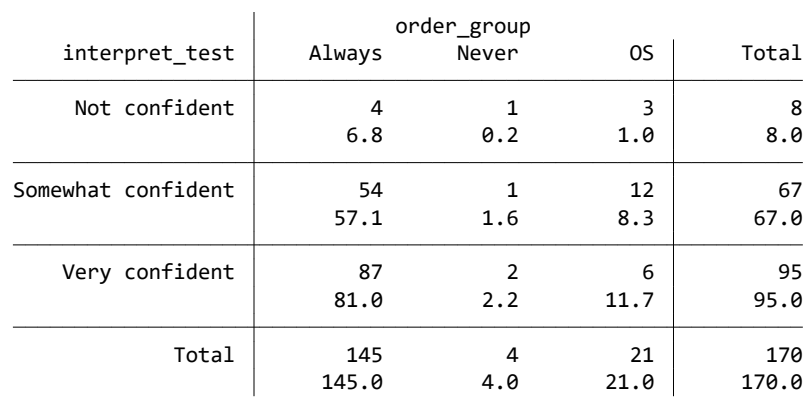

Fisher's exact $=$

0.005

\section{CONFIDENCE COUNSELING A PATIENT ON MEANING}

. tab counsel_test order_group, exact exp

$$
\begin{array}{|c|}
\hline \text { Key } \\
\hline \text { frequency } \\
\text { expected frequency }
\end{array}
$$

Enumerating sample-space combinations:

stage 3: enumerations $=1$

stage 2: enumerations $=12$

stage 1: enumerations $=0$

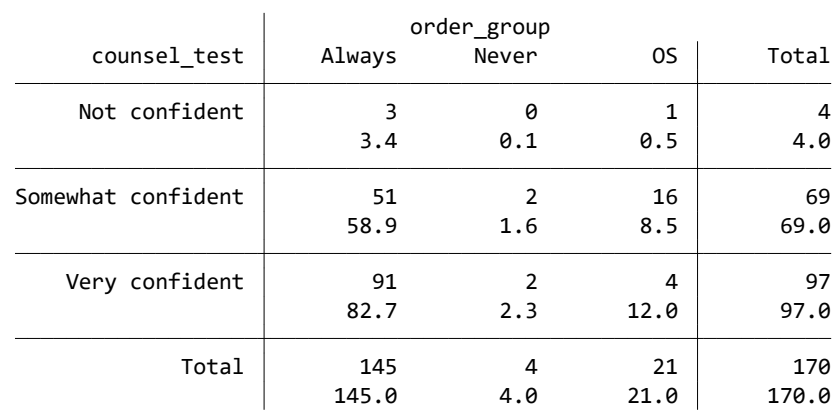

Fisher's exact $=$

$$
0.002
$$




\section{CONFIDENCE DECIDING WHICH PATIENTS TO REFER}

. tab refer order_group, exact exp

\begin{tabular}{|c|}
\hline Key \\
\hline frequency \\
expected frequency \\
\hline
\end{tabular}

Enumerating sample-space combinations:

stage 3: enumerations $=1$

stage 2: enumerations $=0$

stage 1: enumerations $=0$

\begin{tabular}{|c|c|c|c|c|}
\hline \multirow[b]{2}{*}{ refer } & \multicolumn{3}{|c|}{ order_group } & \multirow[b]{2}{*}{ Total } \\
\hline & Always & Never & OS & \\
\hline \multirow[t]{2}{*}{ Somewhat confident } & 22 & 0 & 3 & 25 \\
\hline & 21.3 & 0.6 & 3.1 & 25.0 \\
\hline \multirow[t]{2}{*}{ Very confident } & 123 & 4 & 18 & 145 \\
\hline & 123.7 & 3.4 & 17.9 & 145.0 \\
\hline \multirow[t]{2}{*}{ Total } & 145 & 4 & 21 & 170 \\
\hline & 145.0 & 4.0 & 21.0 & 170.0 \\
\hline
\end{tabular}




\section{Bibliography}

1. Siegel RI, Miller KD, Jemal A. Cancer statistics, 2019. CA: A Cancer Journal for Clinicians. 2019;69(1):7-34.

2. Bell D, Berchuck A, Birrer M, et al. Integrated genomic analyses of ovarian carcinoma. Nature. 2011;474(7353):609-615.

3. Walsh T, Casadei S, Lee MK, et al. Mutations in 12 genes for inherited ovarian, fallopian tube, and peritoneal carcinoma identified by massively parallel sequencing. Proc Natl Acad Sci U S A. 2011;108(44):18032-18037.

4. National Comprehensive Cancer Network. Genetic/Familial High-Risk Assessment: Breast, Ovarian, and Pancreatic (Version 2.2021). Published 2020. Accessed2021.

5. Konstantinopoulos PA, Norquist B, Lacchetti C, et al. Germline and Somatic Tumor Testing in Epithelial Ovarian Cancer: ASCO Guideline. Journal of Clinical Oncology. 2020;38(11):1222-1245.

6. Lancaster JM, Powell CB, Chen LM, Richardson DL. Society of Gynecologic Oncology statement on risk assessment for inherited gynecologic cancer predispositions. Gynecol Oncol. 2015;136(1):3-7.

7. National Comprehensive Cancer Network. Ovarian Cancer (Version 1.2020). https://www.nccn.org/professionals/physician_gls/pdf/ovarian.pdf. Published 2020. Accessed 2021.

8. González-Martín A, Pothuri B, Vergote I, et al. Niraparib in Patients with Newly Diagnosed Advanced Ovarian Cancer. N Engl J Med. 2019;381(25):2391-2402.

9. Woolderink JM, De Bock GH, de Hullu JA, et al. Characteristics of Lynch syndrome associated ovarian cancer. Gynecol Oncol. 2018;150(2):324-330.

10. Buys SS, Partridge E, Black A, et al. Effect of screening on ovarian cancer mortality: the Prostate, Lung, Colorectal and Ovarian (PLCO) Cancer Screening Randomized Controlled Trial. Jama. 2011;305(22):2295-2303.

11. Jacobs IJ, Menon U, Ryan A, et al. Ovarian cancer screening and mortality in the UK Collaborative Trial of Ovarian Cancer Screening (UKCTOCS): a randomised controlled trial. Lancet. 2016;387(10022):945-956.

12. Stewart ME, Knisely AT, Sullivan MW, Ring KL, Modesitt SC. Evaluation of screening and risk-reducing surgery for women followed in a high-risk breast/ovarian cancer clinic: it is all about the tubes in BRCA mutation carriers. Gynecol Oncol Rep. 2019;28:18-22.

13. Dominguez-Valentin M, Sampson JR, Seppälä TT, et al. Cancer risks by gene, age, and gender in 6350 carriers ofpathogenic mismatch repair variants: findings from the Prospective Lynch SyndromeDatabase. Genetics in Medicine. 2020;22(1):15-25.

14. Petrucelli N, Daly MB, Pal T. BRCA1- and BRCA2-Associated Hereditary Breast and Ovarian Cancer. In: Adam MP, Ardinger HH, Pagon RA, et al., eds. GeneReviews(®). Seattle (WA): University of Washington, Seattle; 2016.

15. Penon-Portmann M, Chang J, Cheng M, Shieh JT. Genetics workforce: distribution of genetics services and challenges to health care in California. Genetics in Medicine. 2020;22(1):227-231. 
16. Kurian AW, Ward KC, Howlader N, et al. Genetic Testing and Results in a PopulationBased Cohort of Breast Cancer Patients and Ovarian Cancer Patients. J Clin Oncol. 2019;37(15):1305-1315.

17. Kurian AW, Ward KC, Abrahamse P, et al. Time Trends in Receipt of Germline Genetic Testing and Results for Women Diagnosed With Breast Cancer or Ovarian Cancer, 20122019. Journal of Clinical Oncology. 2021:JCO.20.02785.

18. Rahman B, Lanceley A, Kristeleit RS, et al. Mainstreamed genetic testing for women with ovarian cancer: first-year experience. J Med Genet. 2019;56(3):195-198.

19. Colombo N, Huang G, Scambia G, et al. Evaluation of a Streamlined Oncologist-Led BRCA Mutation Testing and Counseling Model for Patients With Ovarian Cancer. J Clin Oncol. 2018;36(13):1300-1307.

20. Bray F, Ferlay J, Soerjomataram I, Siegel RL, Torre LA, Jemal A. Global cancer statistics 2018: GLOBOCAN estimates of incidence and mortality worldwide for 36 cancers in 185 countries. CA: A Cancer Journal for Clinicians. 2018;68(6):394-424.

21. Bray F, Colombet M, Mery L, et al. Cancer Incidence in Five Continents, Vol. XI (electronic version). Lyon: International Agency for Research on Cancer. https://ci5.iarc.fr. Published 2017. Accessed 2020.

22. Webb PM, Jordan SJ. Epidemiology of epithelial ovarian cancer. Best Practice \& Research Clinical Obstetrics and Gynaecology 2017;41:3-14.

23. Kobayashi H, Yamada Y, Sado T, et al. A randomized study of screening for ovarian cancer: a multicenter study in Japan. Int J Gynecol Cancer. 2008;18(3):414-420.

24. Skates SJ, Greene MH, Buys SS, et al. Early Detection of Ovarian Cancer using the Risk of Ovarian Cancer Algorithm with Frequent CA125 Testing in Women at Increased Familial Risk - Combined Results from Two Screening Trials. Clin Cancer Res. 2017;23(14):3628-3637.

25. Lu KH, Skates S, Hernandez MA, et al. A 2-stage ovarian cancer screening strategy using the Risk of Ovarian Cancer Algorithm (ROCA) identifies early-stage incident cancers and demonstrates high positive predictive value. Cancer. 2013;119(19):3454-3461.

26. Naumann RW, Brown J. Ovarian cancer screening with the Risk of Ovarian Cancer Algorithm (ROCA): Good, bad, or just expensive? Gynecol Oncol. 2018;149(1):117-120.

27. Kurman RJ, Carcangiu ML, Herrington CS, Carcangiu ML. WHO Classification of Tumours of Female Reproductive Organs. Lyon, FRANCE: International Agency for Research on Cancer (I A R C) (UN); 2014.

28. Seidman JD, Horkayne-Szakaly I, Haiba M, Boice CR, Kurman RJ, Ronnett BM. The histologic type and stage distribution of ovarian carcinomas of surface epithelial origin. Int J Gynecol Pathol. 2004;23(1):41-44.

29. Köbel M, Kalloger SE, Huntsman DG, et al. Differences in tumor type in low-stage versus high-stage ovarian carcinomas. Int J Gynecol Pathol. 2010;29(3):203-211.

30. Rojas V, Hirshfield KM, Ganesan S, Rodriguez-Rodriguez L. Molecular Characterization of Epithelial Ovarian Cancer: Implications for Diagnosis and Treatment. Int J Mol Sci. 2016;17(12).

31. Mills PK, Riordan DG, Cress RD. Epithelial ovarian cancer risk by invasiveness and cell type in the Central Valley of California. Gynecol Oncol. 2004;95(1):215-225.

32. Kurman RJ, Shih Ie M. The Dualistic Model of Ovarian Carcinogenesis: Revisited, Revised, and Expanded. Am J Pathol. 2016;186(4):733-747. 
33. Pearce CL, Stram DO, Ness RB, et al. Population distribution of lifetime risk of ovarian cancer in the United States. Cancer Epidemiol Biomarkers Prev. 2015;24(4):671-676.

34. Stratton JF, Pharoah P, Smith SK, Easton D, Ponder BA. A systematic review and metaanalysis of family history and risk of ovarian cancer. $\mathrm{Br} J$ Obstet Gynaecol. 1998;105(5):493-499.

35. Li K, Hüsing A, Fortner RT, et al. An epidemiologic risk prediction model for ovarian cancer in Europe: the EPIC study. Br J Cancer. 2015;112(7):1257-1265.

36. Jervis S, Song H, Lee A, et al. Ovarian cancer familial relative risks by tumour subtypes and by known ovarian cancer genetic susceptibility variants. J Med Genet. 2014;51(2):108113.

37. Collaborative Group on Epidemiological Studies of Ovarian Cancer. Menopausal hormone use and ovarian cancer risk: individual participant meta-analysis of 52 epidemiological studies. Lancet. 2015;385(9980):1835-1842.

38. Pearce CL, Templeman C, Rossing MA, et al. Association between endometriosis and risk of histological subtypes of ovarian cancer: a pooled analysis of case-control studies. Lancet Oncol. 2012;13(4):385-394.

39. Cancer CGoESoO. Ovarian cancer and body size: individual participant meta-analysis including 25,157 women with ovarian cancer from 47 epidemiological studies. PLoS Med. 2012;9(4):e1001200.

40. McGuire V, Hartge P, Liao LM, et al. Parity and Oral Contraceptive Use in Relation to Ovarian Cancer Risk in Older Women. Cancer Epidemiol Biomarkers Prev. 2016;25(7):1059-1063.

41. Collaborative Group on Epidemiological Studies of Ovarian Cancer. Ovarian cancer and oral contraceptives: collaborative reanalysis of data from 45 epidemiological studies including 23,257 women with ovarian cancer and 87,303 controls. Lancet. 2008;371(9609):303-314.

42. Sieh W, Salvador S, McGuire V, et al. Tubal ligation and risk of ovarian cancer subtypes: a pooled analysis of case-control studies. Int J Epidemiol. 2013;42(2):579-589.

43. Chan JK, Urban R, Capra AM, et al. Ovarian cancer rates after hysterectomy with and without salpingo-oophorectomy. Obstet Gynecol. 2014;123(1):65-72.

44. Rebbeck TR, Kauff ND, Domchek SM. Meta-analysis of risk reduction estimates associated with risk-reducing salpingo-oophorectomy in BRCA1 or BRCA2 mutation carriers. J Natl Cancer Inst. 2009;101(2):80-87.

45. Wentzensen N, Poole EM, Trabert B, et al. Ovarian Cancer Risk Factors by Histologic Subtype: An Analysis From the Ovarian Cancer Cohort Consortium. J Clin Oncol. 2016;34(24):2888-2898.

46. Lee JY, Jeon I, Kim JW, Song YS, Yoon JM, Park SM. Diabetes mellitus and ovarian cancer risk: a systematic review and meta-analysis of observational studies. Int J Gynecol Cancer. 2013;23(3):402-412.

47. Faber MT, Kjær SK, Dehlendorff C, et al. Cigarette smoking and risk of ovarian cancer: a pooled analysis of 21 case-control studies. Cancer Causes Control. 2013;24(5):989-1004.

48. Terry KL, Karageorgi S, Shvetsov YB, et al. Genital powder use and risk of ovarian cancer: a pooled analysis of 8,525 cases and 9,859 controls. Cancer Prev Res (Phila). 2013;6(8):811-821.

49. Whiteman DC, Siskind V, Purdie DM, Green AC. Timing of pregnancy and the risk of epithelial ovarian cancer. Cancer Epidemiol Biomarkers Prev. 2003;12(1):42-46. 
50. Luan NN, Wu QJ, Gong TT, Vogtmann E, Wang YL, Lin B. Breastfeeding and ovarian cancer risk: a meta-analysis of epidemiologic studies. Am J Clin Nutr. 2013;98(4):10201031.

51. Dick ML, Siskind V, Purdie DM, Green AC. Incomplete pregnancy and risk of ovarian cancer: results from two Australian case-control studies and systematic review. Cancer Causes Control. 2009;20(9):1571-1585.

52. Braem MG, Onland-Moret NC, Schouten LJ, et al. Multiple miscarriages are associated with the risk of ovarian cancer: results from the European Prospective Investigation into Cancer and Nutrition. PLoS One. 2012;7(5):e37141.

53. Mikkelsen AP, Egerup P, Ebert JFM, Kolte AM, Nielsen HS, Lidegaard Ø. Pregnancy Loss and Cancer Risk: A Nationwide Observational Study. EClinicalMedicine. 2019;15:80-88.

54. Rizzuto I, Behrens RF, Smith LA. Risk of ovarian cancer in women treated with ovarian stimulating drugs for infertility. Cochrane Database Syst Rev. 2019;6(6):Cd008215.

55. Trabert B, Lamb EJ, Scoccia B, et al. Ovulation-inducing drugs and ovarian cancer risk: results from an extended follow-up of a large United States infertility cohort. Fertil Steril. 2013;100(6):1660-1666.

56. Gottschau M, Kjaer SK, Jensen A, Munk C, Mellemkjaer L. Risk of cancer among women with polycystic ovary syndrome: a Danish cohort study. Gynecol Oncol. 2015;136(1):99103.

57. Rasmussen CB, Kjaer SK, Albieri V, et al. Pelvic Inflammatory Disease and the Risk of Ovarian Cancer and Borderline Ovarian Tumors: A Pooled Analysis of 13 Case-Control Studies. Am J Epidemiol. 2017;185(1):8-20.

58. Genkinger JM, Hunter DJ, Spiegelman D, et al. Alcohol intake and ovarian cancer risk: a pooled analysis of 10 cohort studies. Br J Cancer. 2006;94(5):757-762.

59. Whiteman DC, Murphy MF, Cook LS, et al. Multiple births and risk of epithelial ovarian cancer. J Natl Cancer Inst. 2000;92(14):1172-1177.

60. Zheng G, Yu H, Kanerva A, Försti A, Sundquist K, Hemminki K. Familial risks of ovarian cancer by age at diagnosis, proband type and histology. PloS one. 2018;13(10):e0205000e0205000.

61. Alsop K, Fereday S, Meldrum C, et al. BRCA mutation frequency and patterns of treatment response in BRCA mutation-positive women with ovarian cancer: a report from the Australian Ovarian Cancer Study Group. J Clin Oncol. 2012;30(21):2654-2663.

62. Pal T, Permuth-Wey J, Betts JA, et al. BRCA1 and BRCA2 mutations account for a large proportion of ovarian carcinoma cases. Cancer. 2005;104(12):2807-2816.

63. Ramus SJ, Song H, Dicks E, et al. Germline Mutations in the BRIP1, BARD1, PALB2, and NBN Genes in Women With Ovarian Cancer. J Natl Cancer Inst. 2015;107(11).

64. Song H, Dicks E, Ramus SJ, et al. Contribution of Germline Mutations in the RAD51B, RAD51C, and RAD51D Genes to Ovarian Cancer in the Population. J Clin Oncol. 2015;33(26):2901-2907.

65. Schoolmeester JK, Moyer AM, Goodenberger ML, Keeney GL, Carter JM, BakkumGamez JN. Pathologic findings in breast, fallopian tube, and ovary specimens in nonBRCA hereditary breast and/or ovarian cancer syndromes: a study of 18 patients with deleterious germline mutations in RAD51C, BARD1, BRIP1, PALB2, MUTYH, or CHEK2. Hum Pathol. 2017;70:14-26. 
66. Risch HA, McLaughlin JR, Cole DE, et al. Population BRCA1 and BRCA2 mutation frequencies and cancer penetrances: a kin-cohort study in Ontario, Canada. J Natl Cancer Inst. 2006;98(23):1694-1706.

67. Ashour M, Ezzat Shafik H. Frequency of germline mutations in BRCA1 and BRCA2 in ovarian cancer patients and their effect on treatment outcome. Cancer Manag Res. 2019;11:6275-6284.

68. Safra T, Waissengrin B, Borgato L, et al. BRCA mutations and outcome in epithelial ovarian cancer (EOC): experience in ethnically diverse groups. AJHO. 2016;12(9):21-25.

69. Kotsopoulos J, Gronwald J, Karlan B, et al. Age-specific ovarian cancer risks among women with a BRCA1 or BRCA2 mutation. Gynecol Oncol. 2018;150(1):85-91.

70. Kuchenbaecker KB, Hopper JL, Barnes DR, et al. Risks of Breast, Ovarian, and Contralateral Breast Cancer for BRCA1 and BRCA2 Mutation Carriers. JAMA. 2017;317(23):2402-2416.

71. Bonadona V, Bonaïti B, Olschwang S, et al. Cancer risks associated with germline mutations in MLH1, MSH2, and MSH6 genes in Lynch syndrome. Jama. 2011;305(22):2304-2310.

72. Norquist BM, Harrell MI, Brady MF, et al. Inherited Mutations in Women With Ovarian Carcinoma. JAMA Oncology. 2016;2(4):482-490.

73. Niskakoski A, Kaur S, Renkonen-Sinisalo L, et al. Distinct molecular profiles in Lynch syndrome-associated and sporadic ovarian carcinomas. Int J Cancer. 2013;133(11):25962608.

74. Casey MJ, Bewtra C, Lynch HT, Snyder C, Stacy M, Watson P. Phenotypic heterogeneity of hereditary gynecologic cancers: a report from the Creighton hereditary cancer registry. Fam Cancer. 2013;12(4):719-740.

75. Loveday C, Turnbull C, Ramsay E, et al. Germline mutations in RAD51D confer susceptibility to ovarian cancer. Nat Genet. 2011;43(9):879-882.

76. Meindl A, Hellebrand H, Wiek C, et al. Germline mutations in breast and ovarian cancer pedigrees establish RAD51C as a human cancer susceptibility gene. Nat Genet. 2010;42(5):410-414.

77. Rafnar T, Gudbjartsson DF, Sulem P, et al. Mutations in BRIP1 confer high risk of ovarian cancer. Nat Genet. 2011;43(11):1104-1107.

78. Domchek SM, Aghajanian C, Shapira-Frommer R, et al. Efficacy and safety of olaparib monotherapy in germline BRCA1/2 mutation carriers with advanced ovarian cancer and three or more lines of prior therapy. Gynecol Oncol. 2016;140(2):199-203.

79. Yang D, Khan S, Sun Y, et al. Association of BRCA1 and BRCA2 mutations with survival, chemotherapy sensitivity, and gene mutator phenotype in patients with ovarian cancer. Jama. 2011;306(14):1557-1565.

80. Cass I, Baldwin RL, Varkey T, Moslehi R, Narod SA, Karlan BY. Improved survival in women with BRCA-associated ovarian carcinoma. Cancer. 2003;97(9):2187-2195.

81. Eliade M, Skrzypski J, Baurand A, et al. The transfer of multigene panel testing for hereditary breast and ovarian cancer to healthcare: What are the implications for the management of patients and families? Oncotarget. 2017;8(2):1957-1971.

82. De Felice F, Marchetti C, Boccia SM, et al. Risk-reducing salpingo-oophorectomy in BRCA1 and BRCA2 mutated patients: An evidence-based approach on what women should know. Cancer Treat Rev. 2017;61:1-5. 
83. Choi YH, Terry MB, Daly MB, et al. Association of Risk-Reducing SalpingoOophorectomy With Breast Cancer Risk in Women With BRCA1 and BRCA2 Pathogenic Variants. JAMA Oncol. 2021.

84. Aslanian HR, Lee JH, Canto MI. AGA Clinical Practice Update on Pancreas Cancer Screening in High-Risk Individuals: Expert Review. Gastroenterology. 2020;159(1):358362.

85. Wang Q, Peng H, Qi X, Wu M, Zhao X. Targeted therapies in gynecological cancers: a comprehensive review of clinical evidence. Signal Transduction and Targeted Therapy. 2020;5(1):137.

86. National Comprehensive Cancer Network. Genetic/Familial High-Risk Assessment: Colorectal (Version 1.2020). 2020.

87. Burn J, Gerdes AM, Macrae F, et al. Long-term effect of aspirin on cancer risk in carriers of hereditary colorectal cancer: an analysis from the CAPP2 randomised controlled trial. Lancet. 2011;378(9809):2081-2087.

88. Sweeny K, Ghane A, Legg AM, Huynh HP, Andrews SE. Predictors of genetic testing decisions: a systematic review and critique of the literature. J Genet Couns. 2014;23(3):263-288.

89. Biesecker BB, Ishibe N, Hadley DW, et al. Psychosocial factors predicting BRCA1/BRCA2 testing decisions in members of hereditary breast and ovarian cancer families. Am J Med Genet. 2000;93(4):257-263.

90. Metcalfe KA, Fan I, McLaughlin J, et al. Uptake of clinical genetic testing for ovarian cancer in Ontario: a population-based study. Gynecol Oncol. 2009;112(1):68-72.

91. Lerman C, Narod S, Schulman K, et al. BRCA1 testing in families with hereditary breastovarian cancer. A prospective study of patient decision making and outcomes. Jama. 1996;275(24):1885-1892.

92. Botoseneanu A, Alexander JA, Banaszak-Holl J. To test or not to test? The role of attitudes, knowledge, and religious involvement among U.S. adults on intent-to-obtain adult genetic testing. Health Educ Behav. 2011;38(6):617-628.

93. Allen CG, Roberts M, Guan Y. Exploring Predictors of Genetic Counseling and Testing for Hereditary Breast and Ovarian Cancer: Findings from the 2015 U.S. National Health Interview Survey. J Pers Med. 2019;9(2).

94. Jones T, McCarthy AM, Kim Y, Armstrong K. Predictors of BRCA1/2 genetic testing among Black women with breast cancer: a population-based study. Cancer Med. 2017;6(7):1787-1798.

95. Kurian AW, Ward KC, Hamilton AS, et al. Uptake, Results, and Outcomes of Germline Multiple-Gene Sequencing After Diagnosis of Breast Cancer. JAMA Oncol. 2018;4(8):1066-1072.

96. Ladd MK, Peshkin BN, Isaacs C, et al. Predictors of genetic testing uptake in newly diagnosed breast cancer patients. J Surg Oncol. 2020;122(2):134-143.

97. Lodder L, Frets PG, Trijsburg RW, et al. Attitudes and distress levels in women at risk to carry a BRCA1/BRCA2 gene mutation who decline genetic testing. Am J Med Genet A. 2003;119a(3):266-272.

98. White VB, Walsh KK, Foss KS, et al. Genetic Testing for Hereditary Breast Cancer: The Decision to Decline. Am Surg. 2018;84(1):154-160. 
99. Keogh LA, Niven H, Rutstein A, Flander L, Gaff C, Jenkins M. Choosing not to undergo predictive genetic testing for hereditary colorectal cancer syndromes: expanding our understanding of decliners and declining. J Behav Med. 2017;40(4):583-594.

100. Hooker GW, Peay H, Erby L, Bayless T, Biesecker BB, Roter DL. Genetic literacy and patient perceptions of IBD testing utility and disease control: a randomized vignette study of genetic testing. Inflamm Bowel Dis. 2014;20(5):901-908.

101. Kaphingst KA, Blanchard M, Milam L, Pokharel M, Elrick A, Goodman MS. Relationships Between Health Literacy and Genomics-Related Knowledge, Self-Efficacy, Perceived Importance, and Communication in a Medically Underserved Population. $J$ Health Commun. 2016;21 Suppl 1(Suppl 1):58-68.

102. Frey MK, Lee SS, Gerber D, et al. Facilitated referral pathway for genetic testing at the time of ovarian cancer diagnosis: uptake of genetic counseling and testing and impact on patient-reported stress, anxiety and depression. Gynecol Oncol. 2020;157(1):280-286.

103. Hamilton JG, Lobel M, Moyer A. Emotional distress following genetic testing for hereditary breast and ovarian cancer: a meta-analytic review. Health Psychol. 2009;28(4):510-518.

104. Hirschberg AM, Chan-Smutko G, Pirl WF. Psychiatric implications of cancer genetic testing. Cancer. 2015;121(3):341-360.

105. Cooksey JA, Forte G, Benkendorf J, Blitzer MG. The state of the medical geneticist workforce: Findings of the 2003 survey of American Board of Medical Genetics certified geneticists. Genetics in Medicine. 2005;7(6):439-443.

106. American Board of Genetic Counseling. Practice analysis. https://www.abgc.net/fordiplomates/practice-analysis.aspx/. Published 2017. Accessed 2020.

107. Cohen SA, Huziak RC, Gustafson S, Grubs RE. Analysis of Advantages, Limitations, and Barriers of Genetic Counseling Service Delivery Models. Journal of Genetic Counseling. 2016;25(5):1010-1018.

108. Rayes N, Bowen DJ, Coffin T, et al. MAGENTA (Making Genetic testing accessible): a prospective randomized controlled trial comparing online genetic education and telephone genetic counseling for hereditary cancer genetic testing. BMC Cancer. 2019;19(1):648.

109. Joseph G, Beattie MS, Lee R, et al. Pre-counseling education for low literacy women at risk of Hereditary Breast and Ovarian Cancer (HBOC): patient experiences using the Cancer Risk Education Intervention Tool (CREdIT). J Genet Couns. 2010;19(5):447-462.

110. Axilbund JE, Hamby LA, Thompson DB, Olsen SJ, Griffin CA. Assessment of the use and feasibility of video to supplement the genetic counseling process: a cancer genetic counseling perspective. J Genet Couns. 2005;14(3):235-243.

111. Vogel RI, Niendorf K, Petzel S, et al. A patient-centered mobile health application to motivate use of genetic counseling among women with ovarian cancer: A pilot randomized controlled trial. Gynecol Oncol. 2019;153(1):100-107.

112. Douma KF, Smets EM, Allain DC. Non-genetic health professionals' attitude towards, knowledge of and skills in discussing and ordering genetic testing for hereditary cancer. Fam Cancer. 2016;15(2):341-350.

113. Cox SL, Zlot AI, Silvey K, et al. Patterns of cancer genetic testing: a randomized survey of Oregon clinicians. J Cancer Epidemiol. 2012;2012:294730.

114. Beitsch PD, Whitworth PW. Can breast surgeons provide breast cancer genetic testing? An American Society of Breast Surgeons survey. Ann Surg Oncol. 2014;21(13):4104-4108. 
115. Vadaparampil ST, Scherr CL, Cragun D, Malo TL, Pal T. Pre-test genetic counseling services for hereditary breast and ovarian cancer delivered by non-genetics professionals in the state of Florida. Clin Genet. 2015;87(5):473-477.

116. Blazer KR, Macdonald DJ, Culver JO, et al. Personalized cancer genetics training for personalized medicine: improving community-based healthcare through a genetically literate workforce. Genet Med. 2011;13(9):832-840.

117. Ha VTD, Frizzo-Barker J, Chow-White P. Adopting clinical genomics: a systematic review of genomic literacy among physicians in cancer care. BMC Med Genomics. 2018;11(1):18.

118. Ready KJ, Daniels MS, Sun CC, Peterson SK, Northrup H, Lu KH. Obstetrics/gynecology residents' knowledge of hereditary breast and ovarian cancer and Lynch syndrome. $J$ Cancer Educ. 2010;25(3):401-404.

119. Pal T, Cragun D, Lewis C, et al. A statewide survey of practitioners to assess knowledge and clinical practices regarding hereditary breast and ovarian cancer. Genet Test Mol Biomarkers. 2013;17(5):367-375.

120. Cragun D, Besharat AD, Lewis C, Vadaparampil ST, Pal T. Educational needs and preferred methods of learning among Florida practitioners who order genetic testing for hereditary breast and ovarian cancer. J Cancer Educ. 2013;28(4):690-697.

121. Carroll JC, Rideout AL, Wilson BJ, et al. Genetic education for primary care providers: improving attitudes, knowledge, and confidence. Can Fam Physician. 2009;55(12):e9299.

122. Westwood G, Pickering R, Latter S, et al. A primary care specialist genetics service: a cluster-randomised factorial trial. Br J Gen Pract. 2012;62(596):e191-197.

123. Blazer KR, Grant M, Sand SR, MacDonald DJ, Uman GC, Weitzel JN. Effects of a cancer genetics education programme on clinician knowledge and practice. J Med Genet. 2004;41(7):518-522.

124. Weitzel JN, Blazer KR, MacDonald DJ, Culver JO, Offit K. Genetics, genomics, and cancer risk assessment: State of the Art and Future Directions in the Era of Personalized Medicine. CA Cancer J Clin. 2011;61(5):327-359.

125. Brandt R, Ali Z, Sabel A, McHugh T, Gilman P. Cancer genetics evaluation: barriers to and improvements for referral. Genet Test. 2008;12(1):9-12.

126. Prochniak CF, Martin LJ, Miller EM, Knapke SC. Barriers to and motivations for physician referral of patients to cancer genetics clinics. J Genet Couns. 2012;21(2):305-325.

127. Brierley KL, Campfield D, Ducaine W, et al. Errors in delivery of cancer genetics services: implications for practice. Conn Med. 2010;74(7):413-423.

128. Bensend TA, Veach PM, Niendorf KB. What's the harm? Genetic counselor perceptions of adverse effects of genetics service provision by non-genetics professionals. J Genet Couns. 2014;23(1):48-63.

129. Society of Gynecologic Oncology. Committee Opinion No. 716: The Role of the Obstetrician-Gynecologist in the Early Detection of Epithelial Ovarian Cancer in Women at Average Risk. Obstet Gynecol. 2017;130(3):e146-e149.

130. Robson ME, Bradbury AR, Arun B, et al. American Society of Clinical Oncology Policy Statement Update: Genetic and Genomic Testing for Cancer Susceptibility. J Clin Oncol. 2015;33(31):3660-3667.

131. George A, Riddell D, Seal S, et al. Implementing rapid, robust, cost-effective, patientcentred, routine genetic testing in ovarian cancer patients. Scientific Reports. 2016;6(1):29506. 
132. Wright S, Porteous M, Stirling D, et al. Patients' Views of Treatment-Focused Genetic Testing (TFGT): Some Lessons for the Mainstreaming of BRCA1 and BRCA2 Testing. $J$ Genet Couns. 2018;27(6):1459-1472.

133. Kemp Z, Turnbull A, Yost S, et al. Evaluation of Cancer-Based Criteria for Use in Mainstream BRCA1 and BRCA2 Genetic Testing in Patients With Breast Cancer. JAMA Netw Open. 2019;2(5):e194428.

134. Percival N, George A, Gyertson J, et al. The integration of BRCA testing into oncology clinics. Br J Nurs. 2016;25(12):690-694.

135. Centers for Disease Control and Prevention. Tier 1 Genomics Applications and their Importance to Public Health. Published 2014. Accessed2021. 